\title{
Do Foreign Portfolio Capital Flows Affect Domestic Investment? Evidence from Brazil
}

\author{
Jefferson A. Colombo ${ }^{\mathrm{a}, 1}$, Tiago Loncan ${ }^{\mathrm{b}}$, João F. Caldeirac \\ ${ }^{a}$ COPPEAD Business School \\ Federal University of Rio De Janeiro (UFRJ) \\ ${ }^{b}$ Department of Accounting \& Finance \\ University of Strathclyde \\ ${ }^{c}$ Department of Economics \\ Federal University of Rio Grande do Sul (UFRGS) \& CNPq
}

\begin{abstract}
Although there are several direct and indirect theoretical channels through which foreign capital flows may affect domestic investment, empirical evidence remains inconclusive. In this paper, we employ a VARX framework to assess the impact of Equity Foreign Portfolio Investment (EFPI) on domestic investment growth, employing monthly series of capital flows and gross capital formation for the Brazilian economy. Our results suggest that EFPI played a non-negligible role in explaining aggregate investment fluctuations, but only before the 2008 global financial crisis. After the crisis, a period marked first by a shift in economic policy in 2008-09, with substantial increases in government intervention, followed by deterioration in the institutional outlook and political stability in 2014-15, mostly against the backdrop of the Petrobras corruption scandal, unexpected shocks to EFPI no longer led any real effects on investment growth. Whilst, in general, our results vouch for beneficial effects of equity capital flows on investment, this virtuous relationship is likely disturbed by interventionist policies and political unrest.
\end{abstract}

Keywords: Foreign Portfolio Capital Flows; Financial Integration; Aggregate Investment; Global Financial Crisis; Emerging Markets.

JEL code: E22; E44; F62.

\footnotetext{
${ }^{1}$ Corresponding author. E-mail: jacolombo@hotmail.com
} 


\section{Introduction}

Developing countries have long struggled with insufficient capital to finance investments. A promising agenda to tackle the problem was advocated by the IMF and The World Bank in the late 1980s, in series of policy prescriptions set forth by the so-called Washington Consensus. Developing countries were advised to implement capital account liberalizations, allowing foreign equity capital to flow in, thus

promoting integration with global equity markets and financing new capital stock with foreign funds. However, as noted by Aizenman et al. (2007), such recipes for growth eventually became the single most controversial policy prescription, and concerning fostering investments, for most of emerging markets, there is no evidence of a growth bonus associated with increasing the financing share of foreign funds. In line with this view, Bekaert et al. (2016) note that, despite voluminous research on the subject, whether financial globalization produces beneficial real economic effects remains controversial. In this paper, we provide novel evidence to this important debate, by investigating whether foreign portfolio capital flows stimulate investment, using Brazil as a case study.

Foreign equity capital flows allegedly reduce the cost of equity capital in developing markets for the interplay of four main factors: improved risk sharing among local and foreign investors, alleviation of financial constraints as more foreign capital becomes available, increased stock market liquidity and adoption of better corporate governance practices by local firms to attract more sophisticated foreign shareholders. In theory, as emerging countries move from financial autarky and become more open to cross-border finance, physical investment should increase accordingly, as a lower cost of equity capital expands the portfolio of positive NPV investments in the economy (Levine \& Zervos, 1998; Henry, 2000; Chari \& Henry, 2004; Bekaert et al., 2005; Stulz, 2005).

While theories justifying increased investment under greater financial openness are reasonably sound, in practice, the story is more complicated. Instead, foreign portfolio capital is often blamed for disrupting local financial markets, for its short-termed nature exacerbates volatility and instability, actually hindering new investment because firms are reluctant in expanding their capital stocks when they do not trust foreign capital will stay long (Stiglitz, 2000; Singh \& Weisse, 1998). In fact, recent empirical evidence shows that during periods of financial instability, like in the 2008 global financial crisis, foreign equity investors reallocated massive quantities of portfolio capitals from emerging economies to advanced economies (Fratzscher, 2012). As adjusting capital stocks is costly, uncertainty about equity valuations caused by foreign capital sudden reversals might actually discourage new investment. Also, portfolio investment may harm the economy for its pro-cyclicality, as it increases when economies are booming but rapidly retreats when economies are slowing, for overheating exchange rates and for inducing bubbles in real estate and financial asset prices (Aizenman \& Pasricha, 2013). Moreover, empirical evidence strongly suggests that institutional quality plays an important role too, working as a catalyst channeling all the aforementioned benefits from capital flows to real variables, such as economic growth, investment and productivity (Slesman et al., 2015; Ayhan Kose et al., 2011; Bekaert et al., 2011).

The Brazilian experience is an exciting story to study. Like many emerging markets, Brazil expe- 
rienced a surge in foreign capital flows in the 1990s (Cardoso \& Goldfajn, 1998). More recently, in years 2009/2010, increases in capital flows raised concerns related to financial stability and exchange rate overheating, to which Brazil responded with several capital controls on equity and fixed income investments (Chamon \& Garcia, 2016; Jinjarak et al., 2013). Moreover, Brazilian private firms long suffer from credit constraints, relying heavily on internally generated cash flows to finance investments (Terra, 2003). As a response to the 2008 financial crisis, the Brazilian government has sharply increased the supply of subsidized credit from state-owned banks (mainly through BNDES) to the private sector, especially for large firms, a policy of betting on so-called national champions firms, hoping to give a boost to investment. Nevertheless, as of the present moment, there is no evidence this policy has produced any stimulus on investment, but it has notably contributed to the deterioration of fiscal deficits. Together with this dramatic shift in economic philosophy, political risk in Brazil has escalated to severe levels, against the backdrop of the Petrobras scandal, which together with the accusations of fiscal fraud, has led to the impeachment of former President Dilma Roussef, in August 2016.

As the Brazilian economy faces the toughest recession of its modern history, much triggered by the aforementioned events, the country urgently needs alternatives to stimulate investment and deliver growth to make its way out of this crisis. In theory, foreign portfolio capitals offer a promising channel to finance expansions of private capital stock. Whilst there is evidence showing that foreign capitals increase equity valuations and decrease the cost of capital in Brazil (Tabak, 2003; Reis et al., 2010; Sanvicente, 2014; Loncan \& Caldeira, 2015), the crucial question whether foreign capital benefits are channeled to the real economy and plays any role in financing new investments remains to be investigated. In our paper, we address this relevant question, contributing to an important and unsettled debate on the effects of foreign capital flows on domestic investment in emerging markets, previously examined in Bosworth \& Collins (1999), Henry (2000), Laeven (2002), Bekaert et al. (2005), Aizenman et al. (2007), Chari \& Blair Henry (2008), among others. We accord novel evidence from a major destination of capital flows such as Brazil, exploiting a granular and wide monthly dataset spanning from 1996 till 2015. This is an interesting period to study: the economy has experienced mixed cycles, such as surges in capital flows and growth, but also recessions, mostly triggered by troubled shifts in economic philosophy and politics after the great financial crisis and in more recent periods, which have gone against the best practices in capital flows management almost by design.

Our first step in modeling the relation between foreign capital and aggregate investment is to construct a monthly estimate of the Brazilian quarterly gross capital formation series. We do that for two main reasons. First, because we have monthly information available on the main components of the quarterly aggregate investment, following the most recent guidelines of the System of National Accounts 2008 (Nations, 2009). Second, all other macroeconomic variables we use in the models are available on a monthly basis, including foreign equity capital flows. In doing this monthly interpolation of the quarterly investment series, we do not change the properties of the original series, and we significantly increase the number of degrees of freedom in our models, which allows us to enhance the number of estimated parameters and thus improve the fit of the model. 
Following this procedure, we model the effect of foreign portfolio equity capitals on real domestic investment by developing a monthly vector autoregressive model with exogenous variables (VARX). We follow economic theory and standard neoclassical models of investment (see, e.g., Romer, 2012) and consider investment, foreign capital, stock market valuation, real interest rates, the exchange rate between the Brazilian Real and the U.S dollar and the supply of credit as a share of gross domestic product as endogenous variables, modelling them simultaneously according to the transmission mechanisms as follows. Neoclassical models of investment predict investment to be an increasing function of future expected profits, which are embedded in equity valuations. As foreign equity capital decreases the cost of capital, equity valuations soar, expanding the investment opportunity set in the economy. Such higher equity valuations attract new foreign equity investment because foreign investors foresee good opportunities to reap capital gains as stocks appreciate. We also consider endogenously in the model a potential effect of real interest rates and real exchange rates on investment.

Additionally, we include a vector of exogenous variables in our empirical models. Following evidence that shocks to commodity prices produce substantial fluctuations in output levels in emerging markets (Shousha, 2016), we include the IMF commodity prices index to control for the effects of terms of trade shocks on investment growth. We also control for global stock returns, following standard International Asset Pricing Models (ICAPM), as in financially integrated markets the global market risk premium takes on substantial importance in explaining the cost of capital. (Solnik, 1974; Stulz, 1981; Koedijk et al., 2002; Chari \& Henry, 2004). Finally, we include a dummy variable capturing recession periods faced by the Brazilian economy, as when the economy is slowing investment typically weakens.

Our identification strategy on the VARX estimation relies on economic grounds. Because aggregate investment obeys physical constraints, a firm may decide to invest, but measured investment responds with a delay because of the investments' inherent lifecycle (Kilian et al., 2013). Therefore, in our recursive ordering of the endogenous variables in the system - which reduced-form errors we orthogonalize applying the Cholesky decomposition on the residual variance-covariance matrix -, we consider aggregate investment as the top variable in the VAR system. ${ }^{1}$ Because variable ordering is an important aspect in recursively identified models such as ours', we follow Kilian et al. (2013), and set our recursive structure based on economic justification, specifically, tracking the predictions of the neoclassical model of investment (Romer, 2012).

The findings from our empirical analysis show that equity foreign portfolio investment (EFPI) tends to produce beneficial effects on domestic investment. When analyzing the full period covered in our study (1996-2015), we find that a one standard deviation (0.1 percentage point) increase in EFPI to GDP ratio rose investment (gross capital formation) growth by 0.3 p.p. fifteen months ahead, keeping all else equal. This effect, however, changes dramatically when we split our sample in before and after the 2008 financial crisis. Before the crisis, the response of aggregate investment growth to one SD positive

\footnotetext{
${ }^{1}$ In our recursive VAR model, this ordering implies that investment cannot be contemporaneously affected by a shock on other endogenous variables. Investment can, however, respond to lagged innovations on the other endogenous variables.
} 
shock to EFPI/GDP was positive and significant (about 0.4 p.p.). In the after crisis period, foreign capital no longer boosted domestic investment - the cumulative impulse-response functions (COIRFs) show that a one SD increase in EFPI/GDP decreased aggregate investment growth in about 0.3 p.p..

Such duality between pre and post-crisis time windows is consistent with the idea that excessive government intervention in credit markets can neutralize the impact of EFPI on investment, as transfers from Brazilian National Treasury to State-owned Banks increased from $0.9 \%$ of GDP in $2008 \mathrm{~m} 8$ to 9.8\% of GDP in 2015m10. Adding another ingredient to the problem, more recently, mostly from 2014 onwards, political uncertainty escalated in Brazil, culminating in the impeachment of former President Dilma Roussef. Whilst monetary policies in developed countries (low-interest rates since the beginning of the crisis) may have contributed to equity flows to remain at a relatively high levels in Brazil, despite growing public fiscal deficits, lower business confidence and deteriorating political and economic fundamentals, interventionism and political turmoil may help explain why the role of EFPI on aggregate investment changed significantly after the 2008 financial crisis and in more recent periods. ${ }^{2}$

Furthermore, the forecast error variance decomposition (FEVD) analysis shows that only 3\% of movements on aggregate investment in a horizon of fifteen months can be explained away by foreign capital flows, whereas $84 \%$ of such variations are due to lagged investment. Given foreign investments account for nearly $25 \%$ of total stock market capitalization, the contribution of foreign capital in financing real investments, though positive and relevant, seems inefficiently low in economic terms. We observe a similar result even before the crisis, when EFPI had a more pronounced effect in aggregate investment: from $1996 \mathrm{~m} 3$ to $2008 \mathrm{~m} 8$, only about $4 \%$ of the error in the forecast of Brazilian gross capital formation growth is attributed to EFPI. These results suggest that, albeit statistically significant, the impact of EFPI on gross capital formation is economically modest.

To deal with a potential feedback effect between investment and EFPI, we proceed to a Granger causality analysis. Our results suggest that the direction of causation occurs from EFPI to investment, and not the other way around (i.e., we find a unidirectional effect from EFPI to investment). However, just as suggested by the COIRFs and FEVDs analyses, lags of EFPI are only useful for predicting aggregate investment before the 2008 crisis. After the crisis, we can not reject the null hypothesis that lagged values of EFPI are jointly equal to zero in the model.

Finally, we perform a sensitivity analysis of our results. Following Sims (1981) and Luetkepohl (2011), we check if our evidence is robust to different variable ordering in the Choleski decomposition of our VARX system. Assuming aggregate investment at the top and EFPI at the bottom ${ }^{3}$ of the vector of $\mathrm{K}=6$ endogenous variables, we test all the $4 !=4 \times 3 \times 2 \times 1=24$ different model specifications and find

\footnotetext{
${ }^{2}$ This shift in the parameters' signal we find after the crisis is also consistent with recent empirical evidence in VAR models and evaluation of shock transmission (Aastveit et al., 2017).

${ }^{3} \mathrm{As}$ it is discussed later in detail, we assume that aggregate investment can not react contemporaneously to shocks in other endogenous variables because of its inherent rigidity, i.e., it takes time to adjust the capital stock. On the other hand, because of its flexibility (foreigners' transactions in securities are typically very liquid), we assume that EFPI can react immediately to shocks in other variables, such as investment, credit to GDP, real interest rate, real exchange rate and stock returns.
} 
that the cumulative responses of aggregate investment to a shock in EFPI is positive in 100\% (24/24) of the combinations. Moreover, consistent with our previous evidence, the effect of EFPI on investment is more pronounced in the before-crisis period.

Lastly, we discuss how interactions between corporate and public policies may help firms in making the most of the foreign equity investments they receive. We also debate the role of external equity capital in financing investments in infrastructure, in light of the restrictive and deteriorated fiscal reality faced by Brazil in the current period and very likely in years to come. As side contributions, we also find evidence that increased stock market valuations attract more foreign capital flows, what we interpret as an additional component to a virtuous cycle between stock market returns, foreign equity capital flows, and investment: high equity market valuation induce foreign portfolio capitals, which in turn stimulate investment. Overall, the results from our study corroborate the argument that foreign capitals might be helpful in funding investments, leaving an interesting message for economic policymakers, and adding a new piece of evidence to this long-dated academic debate on the pros and cons of liberalizations.

The rest of our paper is organized as follows. Section 2 brings our model specification, data and econometric strategies employed. In section 3 we describe our results, and in Section 4 we discuss its main implications in the Brazilian context. Finally, in section 5, we present the conclusions of our paper.

\section{Methodology and Data}

\subsection{Estimating the Brazilian monthly aggregate investment series}

The aggregate investment rate of the Brazilian economy is calculated by the Brazilian Institute of Geography and Statistics (IBGE) on a quarterly basis, following the publishing schedule of the country's System of Quarterly National Accounts (SQNA). Investment is defined as the gross fixed capital formation and consists of outlays on additions to the fixed assets of the economy plus net changes in the level of inventories (Nations, 2009).

Although investment is only available on a quarterly basis, IBGE discloses monthly estimates of the industrial production level of Brazilian industry sector according to the goods' category of use, comprising equipment (gross capital formation), intermediary goods (intermediate consumption), and consumer goods (durable, non-durable and semi-durable). Whilst real aggregate investment data is not observable on a monthly basis, production of capital goods - which is a proxy for the increase in gross fixed capital formation - is available monthly through the Monthly Industrial Survey (PIM/IBGE). We also observe on a monthly basis another essential component of the domestic aggregate investment: the production of standard construction inputs, such as cement, iron, steel, among others, through another table of the Monthly Industrial Survey (PIM/IBGE). According to IBGE, in the years between 2010 and 2014, capital goods and construction industries taken together accounted for about $89 \%$ of gross total capital of the country. ${ }^{4}$

\footnotetext{
${ }^{4}$ The other $11 \%$ refers to intellectual property products (IPPs - almost 11\%) and net changes in the level of inventories (less than $0.5 \%$ ).
} 
We then construct a monthly investment series based on the evolution of both capital goods and construction inputs production, aggregating the referred series accordingly to their weight in the 20102014 average gross value added. Because these monthly available series represent the evolution of almost $90 \%$ of the gross fixed capital formation, one could expect both monthly and quarterly series to be highly correlated. ${ }^{5}$ However, because both series does not fit perfectly, we improve our monthly estimation by applying the Denton's proportional method (Denton, 1971) to interpolate the quarterly investment series with the high-frequency investment indicator. This method is described as "relatively simple, robust, and well suited for large-scale applications." (Bloem et al., 2001). It is important to note that the indicator series only contribute to the pattern of the interpolated points, not modifying the characteristics of the original series (the quarterly aggregate investment of the Brazilian economy). Technically, the method is a constrained least squares problem, in which the interpolated data obeys the original low-frequency totals (which represents the imposed constraint). Because of these advantages, Denton's proportional method is widely used in countries' SNAs around the world.

The results of the application of the Denton's proportional method are shown in Figure 1. While the line plot represents the estimated monthly series, the scatter plot refers to the original quarterly investment series. Just as expected, both series present the same cyclical pattern and time trends. From 1993m3 to 2005m3, Brazilian investment did not increase its level over time. Starting in 2005, investment rose significantly, interrupting its positive slope temporarily during the 2008 financial crisis, but recovering fast and keeping its upward trend until mid-2013. On early 2014, a severe economic recession imposed a downward trend to aggregate investment, which shows no sign of recovery until our last observation, referred to $2015 \mathrm{~m} 10$.

[Insert Figure 1 around here]

The original series in the investment rate is provided by the IBGE from the first quarter of 1996 (1996Q1) to the third quarter of 2015 (2015Q3), with 79 observations in total. We have 238 observations of our monthly series, starting in 1996M1 and ending in 2015M10. For convenience, our series are shown as an index, in which 2011Q1 is set to be equal to 100 (baseline).

We can infer from Figure 1 that the data is well suited for our investment analysis. For example, during the 2008-2009 financial and economic crisis, the industrial production of capital goods suffered a sharp decrease, the same pattern observed in the gross formation of fixed capital. One could also note that the volatility of the Brazilian industry production has increased recently. In fact, the economic recession that began in $2014^{6}$ caused a sharp drop in the industrial production, especially in the capital goods sector.

\footnotetext{
${ }^{5}$ Indeed, our high-frequency monthly estimate of investment is highly correlated with the original quarterly gross capital formation: the Pearson's linear correlation coefficient during the 1996-2015 period is 0.81 .

${ }^{6}$ In August 4th, 2015, the Brazilian Business Cycle Dating Committee (CODACE) identified a local maximum point (peak) in the Brazilian business cycle in 2014Q2, suggesting that a recessive period started as of the end of that quarter.
} 


\subsection{Data and descriptive statistics}

Following the definition of the aggregate investment series, we calculate our measures of net foreign portfolio investment (EFPI) in Brazil using data from the Securities Exchange Commission of Brazil (CVM) and Central Bank of Brazil (BCB). The net (inflow minus outflow) foreign capital is converted from USD to Brazilian Real ( $\mathrm{R} \$$ ) using the monthly average exchange rate, and then normalized by the 12 month accumulated GDP. ${ }^{7}$ It is important to note that a recent methodological change on National Accounts took place in Brazil, following the IMF recommendations established on the sixth edition of the Balance of Payments and International Investment Position Manual (BPM6). Therefore, our series are the most recent, best available information on foreign capital flows.

In order to estimate the partial effect of equity foreign portfolio investment on domestic aggregate investment, we collect data for market characteristics such as local interest rates (real interest rates RIR, and the annualized spread on the inter-bank deposit rate - SWAP360), real exchange rate (RER), country-specific risk (EMBI+ Brazil), investment opportunities (Consumer Confidence Index - CCI), Brazilian stock market representative index - IBOVESPA, and MSCI index (for both the world and emerging equity markets), U.S. interest rates (Fed Funds Rate and U.S. 10 year bond yield), financial development (Credit-GDP ratio), price of exports and imports (IMF Commodities Price Index and Terms of Trade) and government subsidized credit (mostly transfers from the National Treasury to the Brazilian Development Bank - BNDES). We also include in our models a dummy variable for the recession periods in the Brazilian economy (RECESSION) and a dummy for the 2008 financial crisis. Following the chronology of the global financial recession, this variable takes the value of one starting on September 2008, when Lehman Brothers filing for Chapter 11 bankruptcy protection triggered a spike in interest rate spreads and risk aversion around the world. ${ }^{8}$ We therefore set the 2008CRISIS dummy to be equal to 1 in the period from $2008 \mathrm{~m} 09$ to $2008 \mathrm{~m} 11$, and zero otherwise. The summary of the variables we consider in this study is shown in Table 1.

\section{[Insert Table 1 around here]}

Analysing the descriptive statistics of the variables (Table 2), we can see that the average monthly investment growth $(\triangle I N V E S T M E N T)$ during the full period $(1996 \mathrm{~m} 3-2015 \mathrm{~m} 10)$ is $0.2 \%$, while the median is $0.3 \%$. The minimum value $(-8.0 \%)$ observed in the variable occurred in $2013 \mathrm{~m} 12$, when the Brazilian gross capital formation was already falling ${ }^{9}$, despite the fact that the economic recession began

\footnotetext{
${ }^{7}$ We collect the GDP accumulated in the last 12 months - current prices $(\mathrm{R} \$$ million) from the Time Series Management System of the BCB (series code n. 4382). Because both the numerator (EFPI) and the denominator (12 month GDP) are in current prices, we do not need to adjust these two series by inflation.

${ }^{8}$ The spread between the T-Bill $(3 \mathrm{~m})$ and the Libor $(3 \mathrm{~m})$ rose from around 2.8 percentage points in early September 2008 to a peak of almost 5 percentage points in middle October 2008. In November 2008, following the announcement of the Troubled Asset Relief Program (TARP), the interest rate spreads started to decrease to the pre-Lehman Brothers episode levels.

${ }^{9}$ Even though December is a typical month of low industry levels due to seasonality, our data is seasonally adjusted by the IBGE, and therefore this sharp decrease in aggregate investment is unlikely to be related to this issue. Nevertheless,
} 
only in 2014Q2. Meanwhile, the mean of net foreign portfolio investment-GDP ratio (EFPI-GDP) is $0.1 \%$, ranging from $-0.4 \%(2008 \mathrm{~m} 10)$ to $0.8 \%(2009 \mathrm{~m} 10)$. All other considered variables main statistics are reported in Table 2.

[Insert Table 2 around here]

All the variables included in the model are either stationary or difference-stationary. Details on statistical procedures and tests regarding the adequacy of the model - unit root tests, exogeneity and marginal significance, lag selection, residual autocorrelation and model stability - are reported in the Appendix B: Statistical tests.

\subsection{Modelling the relationship between EFPI and aggregate investment}

We consider the following vector autoregression with exogenous variables of order $(p, q)$, denoted $\operatorname{VARX}_{k, m}(p, q)$ :

$$
\mathbf{y}_{t}=\nu+A_{1} \mathbf{y}_{t-1}+\ldots+A_{p} \mathbf{y}_{t-p}+B_{1} \mathbf{x}_{t}+B_{2} \mathbf{x}_{t-1}+\ldots+B_{q} \mathbf{x}_{t-q}+\boldsymbol{\epsilon}_{t}
$$

where $\left\{\mathbf{y}_{t}\right\}_{t=1}^{T}$ is an $N \times 1$ vector of endogenous variables and we allow for the presence of an $(M \times 1)$ vector of exogenous variables, $\left\{\mathbf{x}_{t}\right\}_{t=1}^{T}$. In equation (1), $\nu$ is an $N \times 1$ vector of intercepts, $A_{j}, j=$ $1, \ldots, p$ and $B_{i}, i=1, \ldots, q$ are $N \times N$ and $N \times M$ matrices of slope coefficients, respectively, and $\epsilon_{t} \sim$ i.i.d. $\left(0, \Sigma_{\epsilon}\right)$ denotes a $N$-dimensional serially uncorrelated error term vector with mean zero and nonsingular covariance matrix $\Sigma_{\epsilon}{ }^{10}$, also referred to as a structural innovation or structural shock. A VAR, which is a special case of the VARX, can be represented by Equation (1) with $B_{j}=0$ for $j=1, \ldots, q$.

Estimation of the parameters of the VARX in (1) requires that both $Y_{t}$ and $X_{t}$ are covariance stationary, i.e., have their first two moments finite and time-invariant. It will be convenient to represent the model by its Vector Moving Average (VMA) form ${ }^{11}$

$$
\mathbf{y}_{t}=\mu+\sum_{i=1}^{\infty} \Lambda_{i} \epsilon_{t-i}+\sum_{i=1}^{\infty} \Psi_{i} \mathbf{x}_{t-i}
$$

where the endogenous variables are expressed as a function of a constant $N$-vector $(\mu)$, and the current and past values of the structural shocks $(\epsilon)$ and the exogenous variables. The $\Psi_{i}$ matrices are the

this period coincides with the first quarter of decline in the Brazilian gross fixed capital formation, which has dropped impressively by $25.0 \%$ from 2013Q3 (peak) to $2015 \mathrm{Q} 4$.

${ }^{10}$ For a moving-average representation of equation (2) to exist, the coefficient matrices $A_{j}$ and $B_{j}$ must be absolutely summable. This can be guaranteed, for example, by taking first differences of the endogenous variables.

${ }^{11}$ The existence of this representation is ensured if the VAR process is stable, i.e., if $y_{t}$ consists of stationary $(\mathrm{I}(0))$ variables. Intuitively, the system's stability ensures that the effect of an impulse in a variable in the system is transitory (see, for example, Luetkepohl (2011) and Baum (2013)). 
dynamic multiplier functions (or transfer functions), and the sequence of moving average coefficients $\Lambda_{i}$ are the simple impulse-response functions (IRFs) at horizon $i$.

In our specific setting, we consider the vector of endogenous variables $\mathbf{y}_{t}=\left[\Delta \mathrm{INV}_{t}, \Delta \mathrm{CRED}-\mathrm{GDP}, \Delta \mathrm{RIR}\right.$, $\left.\Delta \mathrm{RER}_{t}, \ldots, \Delta \mathrm{IBOV}_{t}, \mathrm{EFPI}_{t}\right]^{\prime}$, where $\mathrm{INV}_{t}$ is the aggregate investment, CRED-GDP $t$ is the credit-to-gdp ratio, $\mathrm{RIR}_{t}$ is the real interest rate, $\mathrm{RER}_{t}$ is the real exchange rate, IBOV ${ }_{t}$ is the Brazilian stock market in$\operatorname{dex}(\mathrm{IBOVESPA})$, and $\mathrm{EFPI}_{t}$ is the equity foreign portfolio investment normalized by GDP. Because the residual covariance matrix $\Sigma_{\epsilon}$ is generally not diagonal (i.e., the components of $u_{t}$ are contemporaneously correlated $^{12}$ ), we propose a recursive identification such that:

$$
\left(\begin{array}{c}
\epsilon_{t, \Delta \mathrm{INV}} \\
\epsilon_{t, \Delta \mathrm{CRED}-\mathrm{GDP}} \\
\epsilon_{t, \Delta \mathrm{RIR}} \\
\epsilon_{t, \Delta \mathrm{RER}} \\
\epsilon_{t, \Delta \mathrm{IBOV}} \\
\epsilon_{t, \mathrm{EFPI}}
\end{array}\right)=\left[\begin{array}{cccccc}
\alpha_{11} & 0 & 0 & 0 & 0 & 0 \\
\alpha_{21} & \alpha_{22} & 0 & 0 & 0 & 0 \\
\alpha_{31} & \alpha_{32} & \alpha_{33} & 0 & 0 & 0 \\
\alpha_{41} & \alpha_{42} & \alpha_{43} & \alpha_{44} & 0 & 0 \\
\alpha_{51} & \alpha_{52} & \alpha_{53} & \alpha_{54} & \alpha_{55} & 0 \\
\alpha_{61} & \alpha_{62} & \alpha_{63} & \alpha_{64} & \alpha_{65} & \alpha_{66}
\end{array}\right]\left(\begin{array}{c}
u_{t, 1} \\
u_{t, 2} \\
u_{t, 3} \\
u_{t, 4} \\
u_{t, 5} \\
u_{t, 6}
\end{array}\right)
$$

Where each line can be viewed as an equation (multiplying through each term on the right-hand side), and each reduced-form shock is a weighted average of selected structural shocks. The triangular matrix described in 3 is the Cholesky Decomposition of the variance-covariance matrix of residuals, and it ensures that the error terms on each equation in the system are orthogonal. ${ }^{13}$ This "triangularization" of the VAR was first suggested by Sims (1980), and it became widely used by macroeonometricians over the past decades. Our identification strategy resides in the establishment of an order among system variables that is economically plausible, which meets the most recent recommendations in the macrofinance literature (see, e.g., Stock \& Watson, 2001; Luetkepohl, 2010; Romer, 2012).

Our strategy allows tracing the effects of a shock in variable " $j$ " in time " $t$ " $\left(u_{j t}\right)$ in all variables in the VARX system, keeping all else equal. The frequency of the data also corroborates our choice to impose short-run restrictions in the coefficients to obtain identification - also known as zero restrictions -: if one had annual data, contemporaneous restrictions would likely be more debatable that if it were on a quarterly or monthly basis (Ronayne, 2011). In this kind of VAR study, the classical identification problem (correlation vs. causation) cannot be solved by a purely statistical tool - rather, economic theory or institutional knowledge must be used to solve the identification issue (see, e.g., Stock \& Watson, 2001; Romer, 2012). Even though we try to rely on economic models, our identification scheme does not build on the "natural experiment" literature, which is still a challenge for macroeconomists (Romer, 2012).

\footnotetext{
${ }^{12}$ Because of space constraints, we do not present the covariance matrix of the estimated residuals. However, they seem to be - as expected - correlated across equations (e.g., the correlation between the residuals of the real interest rate and credit-GDP ratio equations is 0.114 ).

${ }^{13}$ If the covariance matrix of structural shocks $\Sigma_{\epsilon}$ is diagonal, the structural shocks are assumed to be uncorrelated. In our VARX system, it means that, e.g., a surprise effect on the equity foreign portfolio investment can affect aggregate domestic investment in the same month, but not the other way around.
} 


\section{Results}

\subsection{VAR coefficients}

We begin our analysis by looking at a model estimated for the full period covered in our study (1996-2015). The results of the estimation of the VARX model are shown in Table 3. According to the model specification, gross capital formation $(\triangle I N V E S T M E N T)$, credit as a share of GDP $(\triangle C R E D-$ $G D P)$, real interest rates $(\triangle R I R)$, real exchange rates $(\triangle R E R)$, stock market valuation $(\triangle I B O V)$ and net equity foreign portfolio investments (EFPI-GDP) are simultaneously and endogenously determined in the VAR system. Additionally, a set of exogenous variables also affect the endogenous variables: commodity prices $(\triangle L 2 . C O M M)$, current global stock market performance $(\triangle M S C I-W D)$, and a dummy capturing periods of recessions in the economy (RECESSION). Our analysis will focus on columns 2 ( $\triangle I N V E S T M E N T)$ and 4 (EFPI-GDP), but we will comment on the effects of foreign capitals on other variables whenever such effects are relevant.

[Insert Table 3 around here]

In the second column of Table 3, the coefficients for $\triangle I N V E S T M E N T$ (our variable of main interest) are reported. In the full period analyzed, the model reveals a strong dependence between current investment growth and past movements of investment growth $(+)$, in line with theories of irreversible investment. We find that real interest rate, a proxy for the real rental price of capital, does not significantly affect changes in the investment levels. This evidence is consistent with other studies evaluating the aggregate investment in Brazil (e.g., Luporini \& Alves (2016)), and suggest that investment responses to past movements in real interest rates are close to zero. Our model also rejects any effects of the supply of credit and exchange rate variations on investment, but we find that investment is affected by past movements of EFPI-GDP $(+)$ and L2. $\triangle C O M M(+)$, and also contemporaneously by RECESSION (-).

As shown in our VAR model, equity foreign portfolio capital flows (EFPI-GDP) exerts a positive and statistically significant effect on investment growth. This finding is consistent with theories of financial integration, as foreign capital flows improve risk sharing between domestic and foreign investors, driving the cost of equity capital downwards and hence increasing investment (Stulz, 2005). Such a result is also in line with prior empirical work, corroborating the argument that foreign capitals may cause investment booms and contribute to economic growth (Henry, 2000; Bekaert et al., 2005). Other variables which entered the model exogenously also help in explaining investment behavior. Investment grows when global commodity prices are high, which is reasonable given the dependence of the Brazilian economy on commodity exports (especially agricultural commodities and basic materials), thus it makes sense that firms increase investments when commodity prices are soaring, for their expected revenues increase. ${ }^{14}$

\footnotetext{
${ }^{14}$ In a recent paper, Shousha (2016) finds that commodity prices shocks are an important source of business cycle fluctuations for emerging markets, especially those classified as net commodity exporters, such as Brazil.
} 
Moreover, investment slows when the economy is facing a recessive period, which follows naturally from standard macroeconomic models.

In column 3, the estimated coefficients for the real exchange rate $(\Delta R E R)$ equation are shown. Foreign capitals affect the real exchange rate between the Brazilian Real and the U.S dollar (-). We interpret this finding as an outcome from the interplay between supply and demand for foreign currency in the domestic exchange market. As foreign capitals cause a greater influx of foreign currency, for foreign investors must buy Brazilian currency to purchase local equities, the relative value of the Brazilian currency appreciates. Such empirical evidence of a statistical effect of foreign capitals on the exchange rate might be seen as a justification backing governmental intervention by means of capital controls, which took place especially between years 2009 and 2011 (Chamon \& Garcia, 2016; Jinjarak et al., 2013).

In column 4 , the estimation results of the stock market valuation equation $(\triangle I B O V)$ are shown. As stock market valuation enters the equation in log differences, coefficients read as partial effects on stocks returns. Foreign equity capital affects stock market returns (-), and the effect occurs with a three periods lag. Such a negative effect of foreign equity capital on expected returns is fully in line with the argument that financial integration brought about by foreign equity capital investments improve risk sharing between foreign and domestic investors, reducing the cost of equity capital. (Buckberg, 1995; Henry, 2000; Bekaert et al., 2005; de Jong \& de Roon, 2005; Carrieri et al., 2007).

The last column of Table 3 shows the results for the equation in which we model the determinants of foreign capital flows (EFPI-GDP). The main determinant of foreign capital flows is $\triangle I B O V$ (lagged stock market valuation) $(+)$. This empirical finding corroborates theories of foreign investor behavior, namely the so-called positive feedback trading hypothesis, which argues that foreign investors adopt momentum strategies, investing when expected capital gains are high due to increases in equity valuations. (Froot et al., 2001; Kaminsky et al., 2004). The variable $\triangle M S C I-W D$, which captures global stock market performance, also affects foreign capital flows $(+)$, hence the Brazilian economy receives more foreign capital when the outlook in global markets is positive. Finally, foreign capitals are influenced by global commodity prices $(+)$, which possibly reflects higher equity valuations of Brazilian stocks when commodity prices soar.

In Table 4 we show the results for the VAR models specified on two different sampling periods. The first period relates to the pre-crisis period and runs from 1996 up to the eve of the crisis, August, 2008 (the month in which the Brazilian equity market was first hit by the global turmoil). The second period goes from December 2008, the month that marks the initial recovery in the Brazilian equity market, up to the end of our sampling period, in October 2015. Panel A refers to the pre-crisis period, whereas Panel B to the post-crisis period.

This analysis shows that the positive effect of foreign capitals on investment growth refers to the pre-crisis period. Comparing the full period with the pre-crisis sub-period, we see that in the pre-crisis period the coefficient is slightly larger (1.29 vs. 1.12), and the statistical significance is stronger $(p<0.05$ vs. $p<0.10)$. In fact, in the post-crisis period, the effect of foreign capitals on investment growth is not statistically different from zero. Thus, it seems that the 2008 financial crisis has somehow interrupted or 
severely affected the ability of foreign capitals to fund the domestic capital stock. We discuss possible reasons behind this shift later on in the paper.

In general, the empirical evidence backed by the coefficients fitted by our VAR analysis provides support for an active role of foreign capitals in financing investment growth. However, the model coefficients and the $R^{2}$ statistics are a first evidence of the effects of each variable in the system only. We follow Stock \& Watson (2001) and revisit these relationships employing more robust analytical techniques. Because of the complicated dynamics in the VAR, Granger-causality tests, impulse response functions and forecast error variance decompositions are more informative than the estimated VAR regression coefficients. We conduct such analyses in the next sections.

\section{[Insert Table 4 around here]}

\subsection{A closer look at causality}

An usual approach to examine the VAR results is to proceed with Granger-Causality tests after the model is fitted (Stock \& Watson, 2001). A variable $\mathrm{x}$ is said to Granger-cause a variable y if, given the past values of $y$, including past values of $\mathrm{x}$ is useful to predict $\mathrm{y}$. The way we test if each endogenous variable in the system Granger-Cause others is to regress $y_{i}, i=1, \ldots, 6$ on its own lags $\left(\operatorname{lag}^{*}=3\right)$ and lagged values of other variables. The null hypothesis of the test is that all estimated coefficients of the lagged values of $\mathrm{x}$ are jointly zero. Failure to reject the null hypothesis is equivalent to failing to reject the hypothesis that $\mathrm{x}$ does not Granger-cause y. Granger causality test for all endogenous variables in the VAR system is shown in Table 5.

\section{[Insert Table 5 around here]}

Again, we focus our analysis on the determinants of aggregate investment growth. In the first column of Table 5, we show Granger causality tests for the full period covered in our study. The model does not do so well in explaining the determinants of the growth in capital formation, at least not for the full period taken altogether, as we do not find any statistically significant causal relationships between investment growth and the other endogenous variables in the model.

However, when looking at the pre and post-crisis sub-periods, we see causalities emerging. In the pre-crisis period, real interest rates $(-)$, foreign capital flows $(+)$ and credit supply $(-)$ Granger-caused investment growth, as the hypothesis of non-causality is rejected for the three variables, at $95 \%$ confidence level for EFPI-GDP and at $90 \%$ level for $\triangle R I R$ and $\triangle C R E D-G D P$. Also, the causality test for all variables jointly rejects the null hypothesis of non-causation at $99 \%$ confidence level.

In the post-crisis period, we see that stock market returns take on more importance in explaining investment growth $(+)$, as $\triangle I B O V$ granger causes investment, and we also find a statistically significant causality of exchange rate variations on investment $(-)$. Again, the joint test of causality for all variables taken together rejects the null hypothesis of non-causation at $99 \%$ confidence level. In line with the 
findings from the VAR coefficient analysis, we do not find any causality running from foreign capitals to investment in the post-crisis period, what reinforces the argument that the role of foreign equity capital in financing investment has changed somehow, interrupting a very beneficial economic relationship between the two variables.

In line with the previous results found in the analysis of the VAR coefficients, we see that movements in stock market returns $(\triangle I B O V)$ Granger-cause foreign capital flows $(+)$, reinforcing the evidence on active feedback trading strategies put in place by foreign investors in the Brazilian equity market. Interestingly, when revisiting our analysis of causalities our findings show once again that foreign capitals cause exchange rate appreciation, but after the crisis only, as we reject the hypothesis that foreign capitals do not Granger-cause exchange rate variations with $90 \%$ confidence interval. This additional piece of evidence corroborates the findings from the analysis of VAR coefficients. Moreover, we do not find any evidence suggesting that investment growth Granger-causes foreign capital flows; hence we can safely state that the causality runs from foreign capitals to investment growth and not the converse.

\subsection{Impulse-Response Functions (IRFs)}

To understand the dynamic properties of domestic investment, we follow the guidelines of Stock \& Watson (2001) and compute impulse response functions (IRFs) for foreign equity capital flows. An IRF traces the impact of a one-time, unit shock to one variable on the current and future values of the endogenous variables. Since the innovations are correlated (as we shall show), they are orthogonalized. ${ }^{15}$ When computing the IRF, we need to choose a specific ordering of the endogenous variables since different orderings may result in different responses. ${ }^{16}$

Impulse-response functions for the recursive VARX are plotted in Figure 2. As our main variable of interest is the aggregate investment, each graph in the figure reflects the cumulative effect of an unexpected one unit increase in one endogenous variable $(k=1,2, \ldots, 6)$ on $\triangle I N V E S T M E N T$, from one to fifteen months ahead. Following Stock \& Watson (2001), we report the point estimates of the COIRFs accompanied by one asymptotic standard error band for each impulse response.

\section{[Insert Figure 2 around here]}

During the full period, Figure 2 indicates that a 1 SD (1.5 p.p.) shock to lagged domestic investment growth lead to an approximately 1.5 p.p. cumulative impact on investment growth, with the response decaying rapidly from month one to month two and more gradually after that. Shocks to foreign equity capital flows and stock market returns also increase investment, but these effects are much weaker (around 0.4 p.p.) when compared to shocks to lagged investment. The response of investment with

\footnotetext{
${ }^{15}$ Specifically, the inverse of the Cholesky decomposition factor of the residual variance-covariance matrix is used to orthogonalize the impulses. This procedure is vital to a "ceteris paribus" analysis: if the residuals are correlated across equations, a shock to one variable will be confounded by the reaction in the other error terms, and therefore we can not have a causal interpretation.

${ }^{16}$ However, the VAR coefficient estimates and the Granger causality results are unaffected by the ordering of variables.
} 
respect to shocks to credit as a share of GDP, real interest rates, and real exchange rates are not statistically different from zero.

When looking at the sub-periods before and after the 2008 crisis (Figure 3), we see very similar dynamics. In fact, the responses we found for the pre-crisis period are nearly equal to the ones for the full period: investment responds strongly to movements of past investments, but marginally to movements of stock returns and foreign equity capital flows. In the post-crisis period, we see that the response to past movements of investment is still strong, but decays more rapidly, and it seems that the supply of credit takes on some non-negligible importance in explaining movements in investment, as now the response of investment to changes in credit as a share of GDP is positive and statistically significant. Though this is good news - after the crisis investment becomes sensitive to expanded credit-, it seems that it came at the expense of the beneficial effect of foreign capital flows, as after the crisis this variable no longer exerts a positive effect on investment growth.

Overall, from the analysis of Impulse Response Functions, we can see that aggregate investment shows a positive, high persistence over time, and thus a positive shock to investment tends to have a positive cumulative effect on its future values, confirming the irreversibility of physical investment hypothesis. Three other variables play a role in determining investment growth: stock market returns, foreign portfolio equity capital flows and supply of credit, but the effect of the later variables is fairly marginal, and are shown to affect investment in different time periods in which the economy was facing different circumstances. In general, all determinants of investment are intimately linked with the neoclassical model, as stock market returns proxy for future expected profits, whereas foreign capitals and supply of credit affect investment through the cost of capital channel. Therefore, to some extent, we find some features of the neoclassical model of investment reflected in our estimates.

[Insert Figure 3 around here]

\subsection{Forecast Variance Error Decomposition (FEVDs)}

According to Stock \& Watson (2001), the forecast variance error decomposition (FEVD) is the percentage of the variance of the error made in forecasting a variable (e.g., aggregate investment) due to a shock in one of the endogenous variables (e.g., EFPI). This variance error is decomposed in a given horizon, usually compatible with the IRF analysis. Since the shocks stabilize after the first months, we compute the FEVDs in the twelve months horizon.

\section{[Insert Table 6 around here]}

Table 6 shows the results of the variance decomposition of forecast errors. Just as suggested by the estimated parameters of the VARX and by the COIRFs, innovations in real aggregate investment are responsible for about $84 \%$ of fluctuations in future investment, revealing a substantial persistence of physical investment. Meanwhile, other factors account for only $6.8 \%$ of the aggregate investment future movements, highlighted by EFPI-GDP (approximately 2.0\%), Ibovespa (1.9\%), and real interest rate 
(around 1.5\%). We can conclude that, even though EFPI is a statistically significant variable in the system, just a small fraction (around 2.0\%) of the forecast error variances of investment are accounted for by innovations in this variable (even so, it is the highest FEVD among all other endogenous variables in the system).

There are differences before and after the crisis, though. Aggregate investment growth shows less persistence after the 2008 financial crisis (Table 6). In this period, innovations to other variables in the system account for $32.7 \%$ of the error variance in the investment equation. We can observe increasing importance of RER in explaining movements in investment, starting three months ahead (ending up accounting for $13.8 \%$ of the variance of forecast errors). As we observe from the IRFs analysis, a positive shock to RER lead to a negative response in investment, especially after the crisis.

Respective to the role of EFPI on investment, the FEVD analysis suggests that it is more important in explaining variations in investment in the pre-crisis period (3.0\% of the error variance 15 -steps ahead) rather than in the post-crisis period (1.3\% 15-steps ahead). These results are consistent with those we find in the IRF analysis and suggest that EFPI played a more important role in explaining future variations in aggregate investment before the 2008 financial crisis, when government interventions in the economy were lower.

\subsection{Sensitivity analysis: Does the variables ordering matter?}

One of the main critiques to the identification of VAR models using the Choleski decomposition of the residual covariance matrix is that IRF results are ordering-dependent (Kilian et al., 2013). The more correlated the residuals are, the more sensible responses can be to different orders of variables in the system. To get things even more complicated, the ordering of variables in impulse response analysis cannot be determined with statistical methods, and thus has to be specified by the analyst (Luetkepohl, 2010). As previously stated, our baseline variable ordering in the VARX system tries to follow economic theory and relies on economic grounds, but ordering is not a trivial task and sometimes can be arbitrary ${ }^{17}$. Since this is an important issue related to the interpretation of the IRFs, we then proceed to check if the results are robust to ordering (a robustness check that is also suggested by Sims (1981)).

In this exercise, we make two assumptions:

- Assumption 1: aggregate investment remains at the top of the vector of the $K=6$ endogenous variables, following the idea that physical investment has a higher degree of rigidity and thus tends to react to shocks in other variables with lags;

\footnotetext{
${ }^{17}$ In our baseline variable ordering, for example, it is assumed that real interest rate is not contemporaneously affected by Ibovespa returns, meanwhile Ibovespa returns are affected by contemporaneous shocks in the real interest rate. One could argue that it is reasonable to expect that Ibovespa returns do have an immediate effect on the real interest rate, and that is why checking different variable ordering becomes important.
} 
- Assumption 2: foreign equity portfolio investment remains at the bottom of the vector of endogenous variables, following the idea that it typically refers to foreigners' transactions in securities/assets that are very liquid, i.e., these securities can be bought and sold easily and fast, and thus it can react immediately to shocks in other variables.

All other endogenous variables $(\triangle C R E D-G D P, \triangle R I R, \triangle R E R$, and $\triangle I B O V)$, are then tested in every possible combination in the model, to check if their order affects our results. Since we have four variables permuting without repetitions, we have $4 !=4 \times 3 \times 2 \times 1=24$ different combinations.

As shown in Figure 4, the results of these tests show that the accumulated orthogonalized response of investment to a shock in foreign equity portfolio investment in the 15 months horizon is positive for $100 \%$ of the combinations $(24 / 24)$. Considering the $68 \%$ confidence interval for the IRFs, we can reject the null hypothesis that the point estimate is equal to zero 15 months after the shock in EFPI in $54.2 \%(13 / 24)$ of the times. Albeit the CI does not affirm there is a statistically significant impact of EFPI in aggregate investment in all cases, the point estimate is always positive, suggesting that our results are not driven by a specific ordering of variables in the Choleski lower triangular decomposition of the residuals. Instead, these simulations reaffirm the magnitude of the impact: a one SD increase in EFPI-GDP ratio (0.1 p.p.) tends to have an accumulated impact on the real aggregate investment growth 15 months ahead of 0.3 p.p., holding all else constant.

\section{[Insert Figure 4 around here]}

We also replicate this ordering robustness check for before and after the structural break imposed by the 2008 financial crisis (not reported because of space constraints). We find that a shock to EFPI caused an average response in aggregate investment growth 15 months ahead of 0.3 p.p. (considering the 24 different model specifications). Before the crisis, it averages 0.4 p.p., while after the crisis the average COIRF drops to -0.3 p.p.. This contrast between pre and post-interventionism suggests that indeed the role of EFPI in aggregate investment changed significantly before and after the crisis, despite of the variables ordering.

Finally, we also calculate the FEVDs for these different variables ordering. On average, the fraction of the forecast errors due to shocks in EFPI is 1.2\% in the full period, $1.5 \%$ before the 2008 financial crisis, and $0.7 \%$ after the crisis, considering the same 24 possible combinations. Taken together, these exercises confirm that EFPI plays a moderated role in explaining future movements in aggregate investment, even before the 2008 financial crisis, when its effects were larger. Therefore, we conclude that our results are qualitatively and quantitatively similar regardless of how variables are ordered in the Choleski decomposition of the covariance matrix of the residuals.

\section{Discussion}

\subsection{Has the role of EFPI in stimulating Investment changed after the GFC?}

The results from our previous analysis show that the role of foreign capitals in financing investment growth suffered a setback after the 2008 great financial crisis (GFC). Figure 5 shows the COIRFs of a 
shock in EFPI to Investment (A) and the Transfers from Brazilian National Treasury to Public Banks as a share of GDP (B). As one could notice, the role of foreign capital flows in affecting aggregate investment indeed seem to have changed dramatically after the 2008 financial crisis.

\section{[Insert Figure 5 around here]}

A fundamental question remains: why has the virtuous cycle between foreign capitals and investment ceased? We offer two arguments. First, the financial crisis has probably interrupted the process of equity market integration in emerging markets. Equity market integration takes time to kick in, and the process might suffer reversals in times of instability (Carrieri et al., 2007). Indeed, as pointed by Fratzscher (2012), the global crisis caused substantial reallocation of capital from emerging back to developed countries, as institutional investors chased safe-haven investments in low-risk countries. Hence, the crisis might have reduced the flow of foreign capital to the Brazilian equity market, and such capital reallocation seems a natural suspect to explain why the effect of foreign capitals on investment has ceased.

Second, the Brazilian government has shifted economic policy in two main grounds after the crisis. First, by increasing subsidies to large firms, second by enacting several capital control measures between years 2009 and 2011, motivated by concerns related to financial instability and exchange rate overheating, precisely because foreign capitals resumed to fly in at pre-crisis levels (or even at higher levels) as global markets settled and investors' confidence was relatively restored. Hence, the very central bank might have armed the trap which prevented foreign capitals to continue financing investment, by taking active measures to reduce foreign capital flows. Indeed, putting together these two arguments, a relevant and current debate in Brazil is whether the increased state intervention in the economy contributed to the recessionary period that started in $2014 \mathrm{~m} 3$ and is still in course, which apparently has its roots in the preceding years.

The so-called "New Economic Matrix" was introduced by President Dilma Roussef through economic incentives for selected industries, without the presence of clear criteria for the granting of benefits such as tax relief. One of the facets of this intervention is the rapid growth of transfers from the National Treasury to Public Banks, which rose from 0.9\% of GDP in 2008m8 to 9.8\% of GDP in $2016 \mathrm{~m} 10$ (see Figure 5 - b). The destination of these resources is also often contested, either because many of the benefited companies are large - which can get credit through private banks or the issue of securities in the capital market - or because there is evidence that these loans are guided by political motivation and their availability coinciding with electoral periods (Carvalho, 2014). For many, the Brazilian model of capitalism converged very close to the "crony capitalism" as described by Zingales (2014), where specific groups see more advantage in investing in lobbying than in expanding their productive activity. As we can see, the recent interventionism may have affected the determinants of aggregate investment, especially those related to private investment.

On top of this shift in economic policy towards stronger interventionism, which is often viewed by foreign investors as a negative signal, the very political outlook has deteriorated a great deal in Brazil, 
against the backdrop of the Petrobras corruption scandal. Figure 6 shows the evolution of the Political Stability Index (International Country Risk Guide), for the period during which the political crisis escalated. In March 2014, the Brazilian federal police launched the now famous Carwash task-force, which soon uncovered the largest bribery scheme in modern Brazilian history, with state-owned oil giant company Petrobras at the epicenter. As more and more politicians from the incumbent party (PT or Partido dos Trabalhadores) got implicated (including former state ministers and party treasurers), the government began to lose support. Despite falling popularity, President Dilma Roussef was re-elected in October/November 2014, but soon after, with the deepening of investigations, government stability plunged again. All culminated with Roussef's impeachment, on the allegations of manipulation of public accounts, fraud and fiscal pedaling. The impeachment process was initiated in December 2015, and concluded after two votes, both in the lower house and in the Senate, in August 2016. In the period between March 2014 and December 2015, Brazil's score on the ICRG Political Stability Index has plunged from 7 to 4 . Given the index runs on a 0-12 scale, the loss in stability was substantial.

[Insert Figure 6 around here]

Whilst government instability likely contributed to the escalation of political risk, political unrest has deleterious effects on capital flows and foreign direct investments (Busse \& Hefeker, 2007; Lensink et al., 2000). Such risks may have added their share to depress capital flows, but also potentially affected the relationship between foreign capitals and investment. Empirical evidence suggests that institutional factors can mediate the effect of foreign capital flows on the real economy (Slesman et al., 2015), as it is often argued that it takes minimum Threshold Effects concerning quality of institutions and financial development so that the benefits from foreign capitals can be channeled to real economic variables. (Ayhan Kose et al., 2011). Given political instability jeopardizes overall institutional quality, political unrest in Brazil might have contributed its share to undermine the beneficial effects of capital flows on investment.

This view is also in line with the agency costs theory. As theorized by Stulz (2005), foreign equity capital is beneficial to emerging economies only if contracting is efficient too and agency costs are mitigated. Such shift towards interventionist policies that occurred in Brazil, together with widespread corruption as uncovered by the Carwash task-force, certainly have raised investors' concerns about government's discretion in extracting benefits from firms, via both official and unofficial channels, the so-called agency cost of state ruler discretion, and this might have increased expropriation risks as perceived by foreign investors. In light of this discussion, agency costs, together with deterioration of government stability, are strong candidates in contributing to nullify the virtuous effects of foreign equity capital flows on investment.

\subsection{Changing composition in portfolio flows}

One remaining question is whether a changing composition in portfolio flows could explain the di-

minishing role of equity portfolio flows on affecting aggregate investment after the GFC. Recent evidence 
suggests that the impact of the euro area crisis on nonresident holdings of domestic debt and the increasing foreign ownership of debt securities issued by emerging markets are main changing factors in capital flows following the global financial crisis (Lane \& Milesi-Ferretti, 2017). From a theoretical perspective, the model developed by Blanchard et al. (2017) suggest that the effects of foreign capital inflows depend very much on their nature: for a given policy rate, bond inflows (e.g., government bonds) appreciate exchange rate and are contractionary; on the other hand, non-bond inflows (e.g., equities and bank liabilities) lead to both an appreciation in the exchange rate and a reduction in the cost of capital. Depending on which effect dominates, such flows may be expansionary. ${ }^{18}$

Using additional data from the Brazilian Balance of Payments (BP), we show in Figure 7 the evolution of both Foreign Portfolio Investment (FPI), Foreign Direct Investment (FDI), and Other Investment ${ }^{19}$ (OI) - Subfigure 7a - and the evolution of the components of FPI - Subfigure 7b. Shaded areas represent recessionary periods in the Brazilian economy. We can infer from the Figure that FDI in Brazil increased significantly after the GFC, averaging 3.56\% of country's GDP, compared to $3.01 \%$ before the GFC. While FDI remains relatively stable, FPI experiences a temporary increase right after the GFC (2009-2010), but then slows down, becoming negative (more outflows than inflows) during the 2014-2016 Brazilian economic recession. Importantly, 7b shows that what drove the reduction in portfolio inflows after the GFC are debt securities; equity flows remained relatively stable after the crisis. This evidence is consistent with the results of Erduman \& Kaya (2016), that point out a structural change after the crisis in bond flows, but not in equity flows.

\section{[Insert Figure 7 around here]}

To account for the type of foreign capital flow and a potential composition effect following the GFC, we use the core VARX model described in Equation 2, but using both debt securities foreign portfolio investment (DSFPI) and total portfolio investment (FPI) instead of equity foreign portfolio investment (EFPI). The resulting orthogonalized impulse-response functions suggest the same pattern observed in Figure 5a: a reversal role of foreign flows after the GFC. We find this result using both the debt component of FPI and total FPI. Therefore, even though there is evidence that many Brazilian firms used global capital markets to substitute foreign equity ownership for debt securities issued abroad, the composition effect does not seem to affect our results regarding the diminishing role of EFPI after the GFC.

\footnotetext{
${ }^{18}$ It is critical to note that the dominant effect depends on the specificities of the host country. In emerging markets, where the financial system is usually underdeveloped, the effect of a reduction in the cost of financial intermediation may dominate (credit boom and output increase). In contrast, in more advanced economies the "appreciation effect" may dominate (Blanchard et al., 2017).

${ }^{19}$ According to the BMP6, p. 111, other investment is "(...) a residual category that includes positions and transactions other than those included in direct investment, portfolio investment, financial derivatives and employee stock options, and reserve assets.
} 


\subsection{Anticipated and unanticipated shocks to foreign equity capital flows}

Akin to our VARX model, the effect of foreign equity capital flows on investment growth is treated as an unanticipated shock. On the other hand, a growing and interesting literature has discussed the potential dual effects of anticipated and unanticipated shocks in affecting real variables, mostly in the context of DSGE models. For instance, while Schmitt-Grohe \& Uribe (2012) provide important guidance on how to identify and estimate unanticipated exogenous shocks to economic fundamentals, Ali \& Anwar (2018) decompose terms of trade shocks to aggregate output as anticipated and unanticipated shocks, and Akhtar et al. (2017) investigate the effect of interest rate surprises on asset and bond prices.

In the context of our study, a VAR methodology such as ours, in contrast with DSGE models, may not be suitable to identify the anticipated component of structural shocks (for a more technical discussion on the shortcomings of VAR in modeling anticipated shocks, see Schmitt-Grohe \& Uribe (2012). Nevertheless, while econometrically decomposing anticipated vis-a-vis unanticipated shocks goes beyond our modeling exercise, it is interesting and important to discuss the economic intuition under which possible effects of anticipated shocks to foreign capital flows may also affect investment.

The underlying rationale of anticipated shocks is that economic agents are forward-looking, reacting to future changes in economic fundamentals before they actually materialize. In the context of foreign capital flows and investment, this logic could imply that firms anticipate booms in foreign equity capital inflows, based on variables predicting such flows, like pull factors internal to the domestic economy, and push factors coming from abroad (Mody et al., 2001). On the other hand, empirical evidence, as previously discussed in the paper, also suggests that capital flows, although pro-cyclical, are highly volatile and often suddenly reverted, thus forecasting inflows and outflows might be complex.

Provided firms could indeed anticipate foreign equity capital flows, it seems possible that anticipated inflows could also affect investment growth. First, firms may enjoy a first-mover advantage when bidding to purchase physical capital, because capital inflows are usually associated with subsequent increases in asset prices. Therefore, those forward-looking firms anticipating a positive influx of foreign capital may anticipate investment to pay a lower price of capital. Second, future foreign capital inflows may be interpreted by local businesses as a signal of the growing confidence of foreign investors in the local economy. Therefore, investment by domestic firms may increase even before foreign equity capital inflows materialize, through this positive expectations channel feeding into future investment opportunities.

In summary, anticipated versus unanticipated shocks to capital flows is definitely an interesting, though complex, extension to our study. The development of a fully-fledged DSGE model, accommodating this duality in anticipated and unanticipated shocks, could be instrumental in addressing these possible effects in future work.

\subsection{Looking to the future: the new Brazilian fiscal reality and the importance of foreign capital flows}

Finally, there are two actual factors related to our paper that deserve attention. First, the expansionary monetary policy adopted by Central Banks of advanced countries after the 2008 financial crisis renewed the debate over policy options in emerging markets to deal with capital flows (Magud et al., 
2014). As of today, such expansionary monetary policies - often still active even though we are now almost ten years away from the crisis - may be a likely scenario for the next years. These low-interest rates in the central financial markets can boost future capital flows to emerging markets.

A second important topic related to foreign capital and its importance to emerging markets in the near future is the infrastructure gap and the lack of funds to finance investments in areas such as highways, ports, and airports. In the Brazilian case, it is estimated that inefficiencies due to inadequate infrastructure impose costs of approximately 10-15\% of the country's GDP (Suisse, 2013). A recent study by Garcia-Escribano et al. (2015) shows that Brazil has inferior overall infrastructure quality relative to almost all its export competitors. From 1980 (around 5\%) to 2013 (around 2\% of GDP), total infrastructure investment (public + private) shrunk considerably. Recent announcements of a new concession project planned by the Federal Government brought reinvigorated expectations on attracting private companies to invest in areas such as transport, energy, and telecommunications (potentially financed with foreign capital). Foreign equity capital can be a powerful ally, for Brazil and also for other emerging markets, in obtaining funding from international capital markets to finance such projects.

\section{Conclusion}

A recurring question debated by academics and policy-makers is whether foreign capital flows to emerging markets have real effects on investment and GDP growth. Although we can cite several theoretical benefits stemming from higher levels of financial integration - e.g., improving risk sharing, alleviating financial constraints, increasing market liquidity, and stimulating better corporate governance practices -, there is still inconclusive evidence vouching for real economic beneficial effects in emerging economies. We contribute new evidence to this important debate and investigate the effects of foreign portfolio capital flows on aggregate investment, using a major emerging market such as Brazil as a case study, covering almost two decades of foreign capitals continuously flowing to the domestic economy (1996-2015), on a monthly basis.

We develop a monthly VARX model, in which investment growth, foreign capital flows, real interest rates, real exchange rates, stock returns and domestic credit supply are modeled simultaneously and endogenously, emphasizing the marginal impact of shocks to foreign portfolio flows on investment growth. We also control for external shocks such as the global financial crisis and commodity prices. Overall, our evidence suggests that equity foreign portfolio investment has a statistically significant impact on investment in Brazil, but this effect seems to be economically modest. From 1996 to 2015, our estimates suggest that a one percentage point positive shock in EFPI-GDP leads to a 0.3 p.p. increase in domestic investment growth, ceteris paribus.

Interestingly, the Brazilian experience shows that the relation between foreign portfolio investment and gross capital formation is time variant and potentially conditional on the degree of government intervention in the economy and on political stability. Following the 2008 financial crisis, transfers from Brazilian National Treasury to State-owned Banks increased from 0.9\% of GDP in 2008m8 to $9.8 \%$ 
of GDP in 2015m10, and the country plunged in a political crisis triggered by the Petrobras scandal, from 2014 onwards. Meanwhile, even though net foreign capital flows remained positive (averaging $0.7 \%$ of GDP after the 2008 financial crisis, then slowing down to $0.3 \%$ at the end of 2015), responses of domestic investment to shocks in EFPI-GDP became substantially weaker. This result is robust to a potential composition effect on portfolio flows (debt securities issued abroad substituting equity), a pattern observed in the post-GFC period.

Such shift in the effect of foreign capital flows on investment observed before and after the 2008 crisis is consistent with the idea that excessive government intervention in credit markets and deterioration in the institutional outlook can neutralize the impact of EFPI on investment. Recent domestic investment behavior suggests that growing fiscal deficits and deterioration in business confidence may dominate the positive effect of foreign capital inflows. Looking forward, Brazilian new fiscal reality and the necessity of expanding infrastructure projects in areas such as energy, transportation, and telecommunications may lead to increasing importance of foreign direct and portfolio investments. In this sense, institutional factors and fiscal sustainability will undoubtedly play a critical role in attracting foreign investors and in shaping the effects of foreign capital on investment and economic growth.

\section{Acknowledgments}

We thank discussants and participants at the Brazilian Finance Society's 2016 Conference and the Jornadas Annuales de Economia's 2017 Conference, and also an anonymous reviewer, for comments which have helped to improve earlier versions of the paper. We are responsible for any eventual errors.

\section{Funding}

Jéfferson A. Colombo gratefully acknowledges support provided by FEE and also CAPES under grant 99999.003202/2014-3. João F. Caldeira acknowledges support provided by CNPq under grants 309899/2015-0 and 430192/2016-9. 


\section{References}

Aastveit, Knut Are, Carriero, Andrea, Clark, Todd E., \& Marcellino, Massimiliano. 2017. Have Standard VARS Remained Stable Since the Crisis? Journal of Applied Econometrics, 32(5), 931-951.

Aizenman, Joshua, \& Pasricha, Gurnain Kaur. 2013. Why do emerging markets liberalize capital outflow controls? Fiscal versus net capital flow concerns. Journal of International Money and Finance, 39(C), 28-64.

Aizenman, Joshua, Pinto, Brian, \& Radziwill, Artur. 2007. Sources for financing domestic capital - Is foreign saving a viable option for developing countries? Journal of International Money and Finance, 26(5), 682-702.

Akhtar, Shumi, Akhtar, Farida, Jahromi, Maria, \& John, Kose. 2017. Impact of interest rate surprises on Islamic and conventional stocks and bonds. Journal of International Money and Finance, 79(C), 218-231.

Ali, Syed Zahid, \& Anwar, SAJid. 2018. Anticipated versus unanticipated terms of trade shocks and the J-curve phenomenon. Journal of International Money and Finance, 81(C), 1-19.

Ayhan Kose, M., Prasad, Eswar S., \& Taylor, Ashley D. 2011. Thresholds in the process of international financial integration. Journal of International Money and Finance, 30(1), 147-179.

Baum, Christopher. 2013. VAR, SVAR and VECM models. Applied Econometrics Notes. Boston.

Bekaert, Geert, Harvey, Campbell R., \& Lundblad, Christian. 2005. Does financial liberalization spur growth? Journal of Financial Economics, 77(1), 3-55.

Bekaert, Geert, Harvey, Campbell R., \& Lundblad, Christian. 2011. Financial Openness and Productivity. World Development, 39(1), 1-19.

Bekaert, Geert, Harvey, Campbell R, Kiguel, Andrea, \& Wang, Xiaozheng. 2016. Globalization and Asset Returns. Annual Review of Financial Economics, 8, 221-288.

Blanchard, Olivier, Ostry, Jonathan D, Ghosh, Atish R, \& Chamon, Marcos. 2017. Are capital inflows expansionary or contractionary? theory, policy implications, and some evidence. IMF Economic Review, 65(3), 563-585.

Bloem, Adriafn M, Dippelsman, Robert, \& Mæhle, Nils Øyvind. 2001. Quarterly national accounts manual: concepts, data sources, and compilation. International Monetary Fund.

Bosworth, Barry P., \& Collins, Susan M. 1999. Capital Flows to Developing Economies: Implications for Saving and Investment. Brookings Papers on Economic Activity, 30(1), 143-180. 
BuckBerg, Elaine. 1995. Emerging Stock Markets and International Asset Pricing. World Bank Economic Review, 9(1), 51-74.

Busse, Matthias, \& Hefeker, Carsten. 2007. Political risk, institutions and foreign direct investment. European Journal of Political Economy, 23(2), 397 - 415.

Calvo, Guillermo A, Leiderman, Leonardo, \& Reinhart, Carmen M. 1996. Inflows of Capital to Developing Countries in the 1990s. The Journal of Economic Perspectives, 10(2), 123-139.

Cardoso, Eliana, \& Goldfajn, Ilan. 1998. Capital Flows to Brazil: The Endogeneity of Capital Controls. IMF Staff Papers, 45(1), 161-202.

Carrieri, Francesca, Errunza, Vihang, \& Hogan, Ked. 2007. Characterizing World Market Integration through Time. Journal of Financial and Quantitative Analysis, 42(04), 915-940.

Carvalho, Daniel. 2014. The Real Effects of Government-Owned Banks: Evidence from an Emerging Market. The Journal of Finance, 69(2), 577-609.

Chamon, Marcos, \& Garcia, Marcio. 2016. Capital controls in Brazil: Effective? Journal of International Money and Finance, 61(C), 163-187.

Chari, Anusha, \& Blair Henry, Peter. 2008. Firm-specific information and the efficiency of investment. Journal of Financial Economics, 87(3), 636-655.

Chari, Anusha, \& Henry, Peter Blair. 2004. Risk Sharing and Asset Prices: Evidence from a Natural Experiment. Journal of Finance, 59(3), 1295-1324.

DE Jong, Frank, \& DE Roon, Frans A. 2005. Time-varying market integration and expected returns in emerging markets. Journal of Financial Economics, 78(3), 583-613.

Denton, Frank T. 1971. Adjustment of monthly or quarterly series to annual totals: an approach based on quadratic minimization. Journal of the American Statistical Association, 66(333), 99-102.

Erduman, Yasemin, \& Kaya, Neslihan. 2016. Time varying determinants of bond flows to emerging markets. Central Bank Review, 16(2), 65-72.

Fratzscher, Marcel. 2012. Capital flows, push versus pull factors and the global financial crisis. Journal of International Economics, 88(2), 341-356.

Froot, Kenneth A., O’Connell, Paul G. J., \& Seasholes, Mark S. 2001. The portfolio flows of international investors. Journal of Financial Economics, 59(2), 151-193.

Garcia-Escribano, Ms Mercedes, Góes, Carlos, \& Karpowicz, Ms Izabela. 2015. Filling the Gap: Infrastructure Investment in Brazil. International Monetary Fund. 
Henry, Peter Blair. 2000. Do stock market liberalizations cause investment booms? Journal of Financial Economics, 58(1-2), 301-334.

Ivanov, Ventzislav, \& Kilian, Lutz. 2005. A practitioner's guide to lag order selection for VAR impulse response analysis. Studies in Nonlinear Dynamics $\&$ Econometrics, 9(1).

Jinjarak, Yothin, Noy, Ilan, \& Zheng, Huanhuan. 2013. Capital controls in Brazil ? Stemming a tide with a signal? Journal of Banking \& Finance, 37(8), 2938-2952.

Kaminsky, Graciela, Lyons, Richard K., \& Schmukler, Sergio L. 2004. Managers, investors, and crises: mutual fund strategies in emerging markets. Journal of International Economics, 64(1), $113-134$.

KILIAN, Lutz, et al. 2013. Structural vector autoregressions. Chapters, 515-554.

Koedijk, Kees G., Kool, Clemens J. M., Schotman, Peter C., \& van Dijk, Mathijs A. 2002. The cost of capital in international financial markets: local or global? Journal of International Money and Finance, 21(6), 905-929.

Laeven, Luc. 2002. Does Financial Liberalization Reduce Financing Constraints? Financial Management, 31(4).

Lane, Mr Philip R, \& Milesi-Ferretti, Mr Gian M. 2017. International financial integration in the aftermath of the global financial crisis. International Monetary Fund.

Lensink, Robert, Hermes, Niels, \& Murinde, Victor. 2000. Capital flight and political risk. Journal of International Money and Finance, 19(1), 73 - 92.

Levine, Ross, \& Zervos, Sara. 1998. Capital Control Liberalization and Stock Market Development. World Development, 26(7), 1169-1183.

Loncan, Tiago Rodrigues, \& Caldeira, JoÏ $<$ O F. 2015. Foreign portfolio capital flows and stock returns: a study of Brazilian listed firms. Estudos Econï£imicos, 45(12), 859 - 895.

Luetkepohl, Helmut. 2010. New Introduction to Multiple Time Series Analysis. New York: SpringerVerlag.

Luetkepohl, Helmut. 2011. Vector Autoregressive Models. Tech. rept. European University Institute.

Luporini, Viviane, \& Alves, Johna. 2016. Investimento privado: uma análise empírica para o Brasil. Economia e Sociedade, 19(3), 449-475.

Magud, Nicolas E, Reinhart, Carmen M, \& Vesperoni, Esteban R. 2014. Capital inflows, exchange rate flexibility and credit booms. Review of Development Economics, 18(3), 415-430. 
Mody, Ashoka, P., Taylor Mark, \& Yeon, Kim Jung. 2001. Modelling fundamentals for forecasting capital flows to emerging markets. International Journal of Finance 6 Economics, 6(3), $201-216$.

Nations, United. 2009. System of National Accounts 2008.

Reis, Luciana, Meurer, Roberto, \& Silva, Sergio Da. 2010. Stock returns and foreign investment in Brazil. Applied Financial Economics, 10(8).

Romer, DAvid. 2012. Advanced macroeconomics. McGraw-Hill/Irwin,.

RonAYNE, DAVID. 2011. Which impulse response function?

Sanvicente, Antonio Zoratto. 2014. The foreign capital flows and the behavior of stock prices at BM\&FBovespa. BAR - Brazilian Administration Review, 11(03), 86 - 106.

Schmitt-Grohe, Stephanie, \& Uribe, Martin. 2012. What's News in Business Cycles. Econometrica, 80(6), 2733-2764.

Shousha, Samer. 2016. Macroeconomic Effects of Commodity Booms and Busts: The Role of Financial Frictions.

Sims, Christopher A. 1980. Macroeconomics and reality. Econometrica: Journal of the Econometric Society, 1-48.

Sims, Christopher A. 1981. An autoregressive index model for the US 1948-1975. Large-Scale MacroEconometric Models, Amsterdam: North-Holland, 1981, 283-327.

Singh, Ajit, \& Weisse, Bruce A. 1998. Emerging stock markets, portfolio capital flows and longterm economie growth: Micro and macroeconomic perspectives. World Development, 26(4), 607-622.

Slesman, Ly, Baharumshah, Ahmad Zubaidi, \& Wohar, Mark E. 2015. Capital inflows and economic growth: does the role of institutions matter? International Journal of Finance 65 Economics, $\mathbf{2 0}(3), 253-275$

Solnik, Bruno H. 1974. An equilibrium model of the international capital market. Journal of Economic Theory, 8(4), 500-524.

StATA, A, et al. 2015. STATA BASE REFERENCE MANUAL RELEASE 14.

Stiglitz, Joseph. 2000. Capital Market Liberalization, Economic Growth, and Instability. World Development, 28(6), 1075-1086.

Stock, James H, \& Watson, Mark W. 2001. Vector autoregressions. The Journal of Economic Perspectives, 15(4), 101-115. 
Stulz, Rene M. 1981. A model of international asset pricing. Journal of Financial Economics, 9(4), 383-406.

Stulz, Rene M. 2005. The Limits of Financial Globalization. Journal of Finance, 60(4), 1595-1638.

Suisse, Credit. 2013. The Brazilian Infrastructure: It's now or Never, (July).

Tabak, Benjamin Miranda. 2003. The random walk hypothesis and the behaviour of foreign capital portfolio flows: the Brazilian stock market case. Applied Financial Economics, 33(4).

Terra, Maria Cristina Trindade. 2003. Credit Constraints in Brazilian Firms: Evidence from Panel Data. Revista Brasileira de Economia, 57(2).

Zingales, Luigi. 2014. A capitalism for the people: Recapturing the lost genius of American prosperity. Basic books. 
Note: This Table summarises the variables used in the study, covering the period from $1996 \mathrm{~m} 3$ to $2015 \mathrm{~m} 10$. We classify each variable in groups according to its economic rationale. In column "Label", " $\Delta$ " means that the variable is measured in differences of the Natural Logarithm transformed data, and thus is expressed in percentage terms (i.e., $\left.\Delta y_{t}=\left[\ln \left(y_{t}\right)-\ln \left(y_{t-1}\right)\right]\right)$. If " $\Delta$ " is not referred, then the variable is expressed in levels. We follow the results of unit root tests to decide when log-differences are needed.

\begin{tabular}{|c|c|c|c|c|c|}
\hline Variable & Label & Detail & Interpretation & Variable Group & Source \\
\hline Domestic Investment & $\triangle$ INVESTMENT & $\begin{array}{l}\text { Monthly estimate of Brazil's real gross } \\
\text { capital formation }\end{array}$ & Domestic Investment & $\begin{array}{l}\text { Dependent } \\
\text { Variable }\end{array}$ & $\begin{array}{l}\text { Authors' calculation } \\
\text { based on IBGE }\end{array}$ \\
\hline $\begin{array}{l}\text { Net Equity Foreign Porfolio } \\
\text { Capital Flows }\end{array}$ & EFPI-GDP & $\begin{array}{l}\text { Monthly net foreign capital flows (inflows minus } \\
\text { outflows) as a percentage of total GDP }\end{array}$ & $\begin{array}{l}\text { Measure of foreign investor's activity } \\
\text { on the stock market }\end{array}$ & $\begin{array}{l}\text { Foreign Capital } \\
\text { Flows }\end{array}$ & CVM and $\mathrm{BCB}$ \\
\hline Real Interest Rate & $\Delta \mathrm{RIR}$ & $\begin{array}{l}\text { Annualized nominal interest rate deflated by } \\
\text { the twelve month accumulated inflation }\end{array}$ & Proxy for Cost of Capital & Cost of Financing & $\mathrm{BCB}$ \\
\hline Swap pre-DI & $\triangle \mathrm{SWAP} 360$ & Annualized spread on the interbank deposit rate & Proxy for Brazilian Risk Free Rate & Cost of Financing & $\mathrm{BCB}$ \\
\hline Real Exchange Rate & $\triangle \mathrm{RER}$ & $\begin{array}{l}\text { Oficial Exchange Rate adjusted for internal } \\
\text { and external price differences over time }\end{array}$ & $\begin{array}{l}\text { Real Price of Domestic Currency } \\
\text { (Brazilian Real) }\end{array}$ & Exchange Rate & World Bank and $\mathrm{BCB}$ \\
\hline Financial Development & $\triangle$ CRED-GDP & Supply of credit / GDP & Proxy for financial development and supply of funds to firms & Financial Development & $\mathrm{BCB}$ \\
\hline Ibovespa Monthly Index & $\triangle \mathrm{IBOV}$ & Local Stock Market Portfolio Index (Ibovespa) & Reflects current and future economic conditions & Investment Opportunities & $\mathrm{BCB}$ \\
\hline $\mathrm{EMBI}+\mathrm{BR}$ & $\Delta$ EMBI-BR & $\begin{array}{l}\text { Spread of Brazilian Bonds over US Bonds } \\
\text { (fixed maturity) }\end{array}$ & Reflects local economy uncertainty & Country Specific Risk & IPEADATA \\
\hline Consumer Confidence Index & $\Delta \mathrm{CCI}$ & $\begin{array}{l}\text { Consumer Confidence Index based on actual } \\
\text { and future economic conditions, } 2010=100\end{array}$ & $\begin{array}{l}\text { General perception about Brazilian economy } \\
\text { on both present and future }\end{array}$ & Investment Opportunities & FGV and Fecomercio/SP \\
\hline Subsidized Credit & $\triangle$ SUBS-GDP & $\begin{array}{l}\text { Subsidized credit in the economy } \\
\text { as a percentage of GDP }\end{array}$ & $\begin{array}{l}\text { Reflects the magnitude of governamental } \\
\text { subsidies to firms' investment }\end{array}$ & Subsidies & $\mathrm{BCB}$ \\
\hline MSCI World & $\triangle$ MSCI-WD & MSCI World Index & $\begin{array}{l}\text { Refers to the global equity } \\
\text { market performance }\end{array}$ & Global Business Cycle & $\mathrm{BCB}$ \\
\hline Fed Funds Rate & $\triangle$ FED-FUNDS & US Federal Funds interest rate (\%) & $\begin{array}{l}\text { Proxy for the "flight-to-quality" movement } \\
\text { of international investors }\end{array}$ & U.S. Short Term Interest Rates & IPEADATA \\
\hline U.S. 10-Year Bond Yield & $\triangle \mathrm{US10YBOND}$ & U.S. 10-Year Bond Yield (\%) & $\begin{array}{l}\text { Proxy for the "flight-to-quality" movement } \\
\text { of international investors }\end{array}$ & U.S. Long-Term Interest Rates & IPEADATA \\
\hline 2008 Financial Crisis & 2008CRISIS & $\begin{array}{c}\text { Dummy that equals } 1 \text { if } 2008 \mathrm{~m} 6 \\
<=t<=2008 \mathrm{~m} 11, \text { and zero otherwise }\end{array}$ & Global financial crisis period & External Shocks & Authors calculation \\
\hline Brazilian Recession Periods & RECESSION & $\begin{array}{l}\text { Dummy that equals } 1 \text { if there is a dated economic } \\
\text { recession in Brazil, and zero otherwise }\end{array}$ & Local Business Cycle & Local Business Cycle & CODACE \\
\hline
\end{tabular}


Table 2: Descriptive Statistics

Note: This table reports the descriptive statistics of our variables for the $1996 \mathrm{~m} 3-2015 \mathrm{~m} 10$ period. All variables shown are stationary, according to the ADF tests. We use the following abbreviations: SD = Standard Deviation, Min = Minimum, Max = Maximum, and $\mathrm{N}=$ Number of observations.

\begin{tabular}{lcccccc}
\hline Variable & Mean & Median & Std Dev & Minimum & Maximum & N \\
\hline$\Delta$ INVESTMENT & 0.002 & 0.003 & 0.015 & -0.080 & 0.037 & 235 \\
EFPI-GDP & 0.001 & 0.000 & 0.001 & -0.004 & 0.008 & 244 \\
$\Delta$ RIR & -0.021 & -0.130 & 2474 & -7.860 & 25.17 & 235 \\
$\Delta$ SWAP360 & -0.027 & -0.040 & 1665 & -8.020 & 10.45 & 235 \\
$\Delta$ CRED-GDP & 0.088 & 0.110 & 0.467 & -3.440 & 1.610 & 235 \\
$\Delta$ SUBS-GDP & 0.041 & 0.000 & 0.201 & -0.200 & 2.000 & 235 \\
$\Delta$ RER & 0.002 & 0.000 & 0.042 & -0.112 & 0.230 & 235 \\
$\Delta$ IBOV & 0.009 & 0.015 & 0.087 & -0.503 & 0.215 & 235 \\
$\Delta$ CCI & -0.001 & 0.002 & 0.051 & -0.254 & 0.169 & 235 \\
$\Delta$ EMBI-BR & -0.003 & -0.017 & 0.116 & -0.301 & 0.522 & 235 \\
$\Delta$ COMM & 0.001 & 0.000 & 0.028 & -0.169 & 0.082 & 235 \\
$\Delta$ MSCI-WD & 0.005 & 0.012 & 0.046 & -0.210 & 0.107 & 235 \\
$\Delta$ FED-FUNDS & -0.021 & 0.000 & 0.168 & -0.960 & 0.280 & 238 \\
$\Delta$ US10YBOND & -0.020 & -0.035 & 0.221 & -1.110 & 0.650 & 238 \\
2008CRISIS & 0.013 & 0.000 & 0.112 & 0.000 & 1.000 & 236 \\
RECESSION & 0.267 & 0.000 & 0.443 & 0.000 & 1.000 & 236 \\
\hline
\end{tabular}


Table 3: Vector Autoregressive Model - Full period (1996-2015)

Note: This table presents the results of the VARX System of simultaneous equations for the period 1996m3-2015m10. Dependent variables are listed in the columns ( $\triangle I N V E S T M E N T, \triangle C R E D-G D P, \triangle R I R, \triangle R E R, \triangle I B O V$, and EFPI-GDP) and represent each equation of the dynamic system. We select the optimum lag length according to AIC plus testing for autocorrelation in residuals using a Lagrange Multiplier (LM) test. If residuals are autocorrelated, we include one extra lag to the model until we do not reject the null hypothesis that there is no residual autocorrelation in the model (our optimum lag length following this criteria is lag $=3$ ). The estimated coefficients and the $t$-statistics (in parentheses) are reported for each independent variable. ${ }^{* * *},{ }^{* *}$, and ${ }^{*}$ implies significance at the $99 \%, 95 \%$ and $90 \%$ levels, respectively.

\begin{tabular}{|c|c|c|c|c|c|c|}
\hline Variable & $\triangle I N V E S T M E N T$ & $\triangle C R E D I T-G D P$ & $\Delta R I R$ & $\triangle R E R$ & $\triangle I B O V$ & EFPI-GDP \\
\hline L. $\triangle I N V E S T M E N T$ & $0.787^{* * *}$ & 2.098 & 3.618 & $-0.405^{*}$ & -0.177 & -0.002 \\
\hline L2. $\triangle I N V E S T M E N T$ & $-0.341^{* * *}$ & $6.110^{*}$ & 18.065 & 0.443 & -0.396 & 0.005 \\
\hline L3. $\triangle I N V E S T M E N T$ & -0.030 & -2.608 & -7.948 & -0.216 & 0.062 & 0.006 \\
\hline L. $\triangle C R E D-G D P$ & -0.001 & $0.111^{* * *}$ & -0.548 & -0.005 & 0.008 & 0.000 \\
\hline $\mathrm{L} 2 . \triangle C R E D-G D P$ & -0.002 & -0.005 & 0.298 & $0.015^{* * *}$ & 0.002 & -0.000 \\
\hline L3. $\triangle C R E D-G D P$ & 0.001 & $0.111^{*}$ & 0.273 & 0.001 & 0.001 & 0.000 \\
\hline L. $\Delta R I R$ & -0.000 & $-0.072^{* * *}$ & $0.109^{*}$ & 0.001 & $0.003^{*}$ & -0.000 \\
\hline $\mathrm{L} 2 . \Delta R I R$ & 0.000 & 0.017 & $-0.167^{* *}$ & -0.001 & $-0.003^{*}$ & 0.000 \\
\hline L3. $\Delta R I R$ & 0.000 & 0.013 & -0.033 & -0.000 & -0.003 & 0.000 \\
\hline L. $\triangle R E R$ & -0.008 & -0.618 & $-7.067 *$ & $0.317^{* * *}$ & 0.079 & -0.001 \\
\hline $\mathrm{L} 2 . \Delta R E R$ & -0.015 & -0.565 & -0.925 & -0.104 & 0.088 & 0.003 \\
\hline $\mathrm{L} 3 . \Delta R E R$ & -0.004 & -0.524 & -2.553 & -0.009 & -0.150 & -0.002 \\
\hline L. $\triangle I B O V$ & 0.005 & -0.555 & $-9.934^{* * *}$ & 0.010 & -0.032 & $0.004^{* * *}$ \\
\hline $\mathrm{L} 2 . \triangle I B O V$ & 0.000 & -0.605 & 2.128 & -0.046 & 0.088 & 0.001 \\
\hline $\mathrm{L} 3 . \triangle I B O V$ & 0.008 & 0.085 & $-3.525^{*}$ & $-0.088^{* * *}$ & -0.053 & -0.000 \\
\hline L.EFPI-GDP & $1.126^{*}$ & -3.559 & -127.815 & -2.549 & 0.280 & 0.021 \\
\hline L2.EFPI-GDP & -0.256 & -3.996 & -124.021 & $-4.270^{*}$ & -2.686 & 0.106 \\
\hline L3.EFPI-GDP & 0.648 & -40.926 & 125.756 & 1.905 & $-6.571 *$ & 0.088 \\
\hline$\triangle L 2 . C O M M$ & $0.061^{* *}$ & 0.558 & -6.092 & $-0.223^{* *}$ & 0.011 & $0.005^{*}$ \\
\hline$\triangle M S C I-W D$ & 0.005 & $-2.049^{* * *}$ & 3.395 & 0.069 & $1.336^{* * *}$ & $0.009^{* * *}$ \\
\hline RECESSION-Dummy & $-0.007^{* * *}$ & -0.069 & 0.328 & 0.000 & -0.015 & -0.000 \\
\hline CONSTANT & $0.002^{* *}$ & $0.130^{* * *}$ & 0.024 & 0.005 & $0.011^{*}$ & $0.000^{* * *}$ \\
\hline RMSE & 0.009 & 0.422 & 2.292 & 0.0347 & 0.063 & 0.001 \\
\hline $\bar{R}^{2}$ & 0.670 & 0.258 & 0.215 & 0.371 & 0.530 & 0.302 \\
\hline$\chi^{2}$ & 471.78 & 80.63 & 63.58 & 136.96 & 262.23 & 100.53 \\
\hline$P>\chi^{2}$ & 0.000 & 0.000 & 0.000 & 0.000 & 0.000 & 0.000 \\
\hline Observations & 232 & 232 & 232 & 232 & 232 & 232 \\
\hline
\end{tabular}


Table 4: VAR Models - Two sub-periods (pre and post 2008 financial crisis)

Note: This table presents the results of the VAR System of simultaneous equations for the period 1996m3-2015m10. Dependent variables are listed in the columns $(\triangle I N V E S T M E N T, \triangle C R E D-G D P, \triangle R I R, \triangle R E R, \triangle I B O V$, and EFPI-GDP) and represent each equation of the dynamic system. We select the optimum lag length according to AIC plus testing for autocorrelation in residuals using a Lagrange Multiplier (LM) test. If residuals are autocorrelated, we include one extra lag to the model until we do not reject the null hypothesis that there is no residual autocorrelation in the model (our optimum lag length following this criteria is $l a g=3$ ). The estimated coefficients and the $\mathrm{t}$ statistics (in parentheses) are reported for each independent variable. ${ }^{* * *},{ }^{* *}$, and ${ }^{*}$ implies significance at the $99 \%, 95 \%$ and $90 \%$ levels, respectively.

\begin{tabular}{|c|c|c|c|c|c|c|c|c|c|c|c|c|}
\hline \multirow{2}{*}{ Variable } & \multicolumn{6}{|c|}{ PANEL A: Before the financial crisis $(1996 \mathrm{~m} 3-2008 \mathrm{~m} 08)$} & \multicolumn{6}{|c|}{ PANEL B: After the financial crisis $(2008 \mathrm{~m} 12-2015 \mathrm{~m} 10)$} \\
\hline & $\triangle I N V E S T M E N T$ & $\triangle C R E D-G D P$ & $\Delta R I R$ & $\triangle R E R$ & $\triangle I B O V$ & EFPI-GDP & $\triangle I N V E S T M E N T$ & $\triangle C R E D-G D P$ & $\Delta R I R$ & $\triangle R E R$ & $\triangle I B O V$ & EFPI-GDP \\
\hline L. $\triangle I N V E S T M E N T$ & $0.768^{* * *}$ & 6.864 & 10.438 & -0.221 & 0.053 & -0.007 & $0.724^{* * *}$ & -2.294 & 1.008 & $-0.616^{* *}$ & 0.293 & 0.015 \\
\hline L2. $\triangle I N V E S T M E N T$ & $-0.211^{* *}$ & -1.964 & 33.981 & 0.501 & -0.796 & 0.019 & $-0.336^{* *}$ & $9.159^{* * *}$ & 1.599 & 0.413 & -0.571 & -0.007 \\
\hline L3. $\triangle I N V E S T M E N T$ & 0.018 & 1.928 & -13.321 & -0.395 & 0.178 & 0.000 & $-0.241^{* *}$ & 0.481 & 4.303 & -0.443 & -0.059 & 0.013 \\
\hline L. $\triangle C R E D-G D P$ & $-0.002^{* *}$ & 0.093 & -0.593 & -0.005 & 0.012 & 0.000 & $0.010^{* *}$ & -0.074 & -0.217 & -0.012 & -0.003 & $0.001^{* *}$ \\
\hline $\mathrm{L} 2 . \triangle C R E D-G D P$ & -0.001 & -0.005 & 0.532 & 0.010 & 0.003 & -0.000 & 0.004 & -0.130 & -0.049 & $0.027^{* *}$ & 0.005 & $0.001 *$ \\
\hline L3. $\triangle C R E D-G D P$ & 0.002 & 0.012 & 0.414 & 0.003 & 0.002 & 0.000 & 0.002 & $0.441^{* * *}$ & -0.106 & $-0.020^{* *}$ & 0.002 & 0.001 \\
\hline L. $\Delta R I R$ & $-0.000^{* *}$ & $-0.071^{* * *}$ & 0.080 & 0.001 & 0.003 & -0.000 & $0.006^{* *}$ & -0.005 & $0.513^{* * *}$ & 0.000 & 0.005 & -0.000 \\
\hline $\mathrm{L} 2 . \Delta R I R$ & 0.000 & 0.018 & $-0.173^{* *}$ & -0.001 & $-0.004^{*}$ & -0.000 & -0.003 & -0.036 & 0.058 & 0.009 & -0.008 & 0.000 \\
\hline L3. $\Delta R I R$ & 0.000 & 0.017 & -0.030 & -0.001 & $-0.003^{*}$ & 0.000 & -0.002 & -0.026 & -0.129 & $-0.016^{* *}$ & 0.001 & 0.001 \\
\hline L. $\triangle R E R$ & -0.011 & -0.913 & -9.541 & $0.441^{* * *}$ & $0.278^{*}$ & -0.001 & $-0.074^{*}$ & -1.146 & -0.512 & 0.083 & -0.162 & 0.000 \\
\hline $\mathrm{L} 2 . \Delta R E R$ & -0.005 & -0.356 & -1.036 & $-0.154^{*}$ & 0.015 & 0.003 & $-0.064^{*}$ & -1.142 & -0.642 & -0.074 & 0.241 & 0.002 \\
\hline L3. $\triangle R E R$ & -0.016 & -0.872 & -5.510 & 0.054 & -0.031 & -0.003 & -0.021 & 0.609 & 1.577 & -0.099 & -0.111 & -0.000 \\
\hline L. $\triangle I B O V$ & -0.008 & -0.562 & $-11.986^{* * *}$ & 0.014 & -0.068 & $0.003^{* * *}$ & $0.055^{* * *}$ & -0.348 & -0.793 & 0.037 & 0.029 & $0.007^{* * *}$ \\
\hline $\mathrm{L} 2 . \triangle I B O V$ & -0.003 & -0.532 & 2.759 & -0.032 & 0.081 & 0.001 & 0.017 & 0.720 & -0.845 & $-0.148^{* * *}$ & 0.003 & 0.001 \\
\hline $\mathrm{L} 3 . \triangle I B O V$ & $0.015^{* *}$ & -0.089 & -2.740 & $-0.121^{* * *}$ & -0.095 & -0.000 & -0.017 & $0.874^{*}$ & -0.824 & -0.027 & -0.064 & 0.001 \\
\hline L.EFPI-GDP & $1.292^{* *}$ & -11.534 & -306.246 & -1.765 & 0.121 & -0.044 & -0.072 & -31.996 & -22.319 & -0.932 & 4.601 & -0.059 \\
\hline L2.EFPI-GDP & -0.689 & -15.539 & -332.164 & -1.380 & -3.045 & 0.099 & -0.348 & -27.027 & 11.919 & $-4.610^{* *}$ & 2.540 & 0.029 \\
\hline L3.EFPI-GDP & 0.997 & -5.054 & 98.566 & 2.100 & -4.687 & 0.059 & -0.815 & $-73.349^{* * *}$ & 25.664 & 2.536 & -2.932 & 0.055 \\
\hline $\mathrm{L} 2 . \triangle C O M M$ & -0.011 & 2.239 & -15.398 & -0.012 & 0.204 & 0.001 & $0.128^{* * *}$ & -0.362 & -1.241 & $-0.363^{* * *}$ & -0.244 & $0.010^{* *}$ \\
\hline$\triangle M S C I-W D$ & 0.004 & $-2.223^{* *}$ & 2.973 & 0.100 & $1.711^{* * *}$ & $0.007^{* * *}$ & -0.005 & $-1.164^{*}$ & 0.005 & 0.064 & $0.898^{* * *}$ & 0.005 \\
\hline RECESSION & $-0.006^{* * *}$ & -0.132 & 0.548 & 0.000 & $-0.028^{* *}$ & -0.000 & $-0.009^{* * *}$ & 0.054 & 0.035 & -0.001 & 0.002 & 0.000 \\
\hline CONSTANT & $0.002^{* *}$ & 0.090 & 0.230 & 0.003 & $0.019^{* * *}$ & $0.000^{* * *}$ & 0.002 & $0.212^{* * *}$ & 0.028 & 0.006 & -0.011 & 0.000 \\
\hline $\bar{R}^{2}$ & 0.657 & 0.279 & 0.273 & 0.329 & 0.580 & 0.245 & 0.774 & 0.469 & 0.440 & 0.691 & 0.560 & 0.418 \\
\hline RMSE & 0.007 & 0.491 & 2.856 & 0.038 & 0.069 & 0.001 & 0.010 & 0.250 & 0.356 & 0.025 & 0.044 & 0.001 \\
\hline Observations & 146 & 146 & 146 & 146 & 146 & 146 & 83 & 83 & 83 & 83 & 83 & 83 \\
\hline
\end{tabular}


Table 5: Granger Causality Tests

Note: This table presents the results of the Granger-causality tests conducted after the estimation of the VAR System of simultaneous equations. We test if each endogenous variable in the system Granger-Cause others by regressing $y_{i}, i=1, \ldots, 6$ on its own lags $\left(l a g^{*}=3\right)$ and on lagged values of other variables. The null hypothesis of the test is that all estimated coefficients of the lagged values of $\mathrm{x}$ are jointly zero. Failure to reject the null hypothesis is equivalent to failing to reject the hypothesis that $x$ does not Granger-cause $y .{ }^{* * *},{ }^{* *}$, and ${ }^{*}$ implies significance at the $99 \%, 95 \%$ and $90 \%$ levels, respectively. All variables in tests are stationary (we suppress the " $\Delta$ " symbol because of space constraints, but it is applied to INVESTMENT, CRED-GDP, RIR, RER, and IBOV).

\begin{tabular}{|c|c|c|c|c|c|c|c|c|}
\hline \multicolumn{3}{|c|}{ Full period } & \multicolumn{3}{|c|}{ Before 2008 crisis } & \multicolumn{3}{|c|}{ After 2008 crisis } \\
\hline Equation & Excluded & Prob & Equation & Excluded & Prob & Equation & Excluded & Prob \\
\hline INVESTMENT & CRED-GDP & 0.418 & INVESTMENT & CRED-GDP & 0.073 & INVESTMENT & CRED-GDP & 0.113 \\
\hline INVESTMENT & RIR & 0.375 & INVESTMENT & RIR & 0.055 & INVESTMENT & RIR & 0.183 \\
\hline INVESTMENT & RER & 0.628 & INVESTMENT & RER & 0.507 & INVESTMENT & RER & 0.054 \\
\hline INVESTMENT & IBOV & 0.719 & INVESTMENT & IBOV & 0.148 & INVESTMENT & IBOV & 0.019 \\
\hline INVESTMENT & EFPI-GDP & 0.112 & INVESTMENT & EFPI-GDP & 0.036 & INVESTMENT & EFPI-GDP & 0.811 \\
\hline INVESTMENT & ALL & 0.174 & INVESTMENT & ALL & 0.002 & INVESTMENT & ALL & 0.007 \\
\hline CRED-GDP & INVESTMENT & 0.025 & CRED-GDP & INVESTMENT & 0.427 & CRED-GDP & INVESTMENT & 0.000 \\
\hline CRED-GDP & RIR & 0.000 & CRED-GDP & RIR & 0.000 & CRED-GDP & RIR & 0.828 \\
\hline CRED-GDP & RER & 0.457 & CRED-GDP & RER & 0.513 & CRED-GDP & RER & 0.226 \\
\hline CRED-GDP & IBOV & 0.181 & CRED-GDP & IBOV & 0.486 & CRED-GDP & IBOV & 0.139 \\
\hline CRED-GDP & EFPI-GDP & 0.461 & CRED-GDP & EFPI-GDP & 0.980 & CRED-GDP & EFPI-GDP & 0.001 \\
\hline CRED-GDP & ALL & 0.000 & CRED-GDP & ALL & 0.000 & CRED-GDP & ALL & 0.000 \\
\hline RIR & INVESTMENT & 0.534 & RIR & INVESTMENT & 0.508 & RIR & INVESTMENT & 0.181 \\
\hline RIR & CRED-GDP & 0.319 & RIR & CRED-GDP & 0.369 & RIR & CRED-GDP & 0.485 \\
\hline RIR & RER & 0.279 & RIR & RER & 0.248 & RIR & RER & 0.495 \\
\hline RIR & IBOV & 0.000 & RIR & IBOV & 0.000 & RIR & IBOV & 0.298 \\
\hline RIR & EFPI-GDP & 0.551 & RIR & EFPI-GDP & 0.380 & RIR & EFPI-GDP & 0.762 \\
\hline RIR & ALL & 0.000 & RIR & ALL & 0.000 & RIR & ALL & 0.305 \\
\hline RER & INVESTMENT & 0.393 & RER & INVESTMENT & 0.742 & RER & INVESTMENT & 0.098 \\
\hline RER & CRED-GDP & 0.033 & RER & CRED-GDP & 0.393 & RER & CRED-GDP & 0.004 \\
\hline RER & RIR & 0.658 & RER & RIR & 0.394 & RER & RIR & 0.227 \\
\hline RER & IBOV & 0.020 & RER & IBOV & 0.016 & RER & IBOV & 0.015 \\
\hline RER & EFPI-GDP & 0.123 & RER & EFPI-GDP & 0.855 & RER & EFPI-GDP & 0.102 \\
\hline RER & ALL & 0.000 & RER & ALL & 0.010 & RER & ALL & 0.000 \\
\hline IBOV & INVESTMENT & 0.485 & IBOV & INVESTMENT & 0.702 & IBOV & INVESTMENT & 0.469 \\
\hline IBOV & CRED-GDP & 0.869 & IBOV & CRED-GDP & 0.734 & IBOV & CRED-GDP & 0.990 \\
\hline IBOV & RIR & 0.014 & IBOV & RIR & 0.019 & IBOV & RIR & 0.954 \\
\hline IBOV & RER & 0.375 & IBOV & RER & 0.203 & IBOV & RER & 0.305 \\
\hline IBOV & EFPI-GDP & 0.342 & IBOV & EFPI-GDP & 0.866 & IBOV & EFPI-GDP & 0.542 \\
\hline IBOV & ALL & 0.109 & IBOV & ALL & 0.249 & IBOV & ALL & 0.804 \\
\hline EFPI-GDP & INVESTMENT & 0.384 & EFPI-GDP & INVESTMENT & 0.247 & EFPI-GDP & INVESTMENT & 0.400 \\
\hline EFPI-GDP & CRED-GDP & 0.834 & EFPI-GDP & CRED-GDP & 0.732 & EFPI-GDP & CRED-GDP & 0.035 \\
\hline EFPI-GDP & RIR & 0.875 & EFPI-GDP & RIR & 0.840 & EFPI-GDP & RIR & 0.114 \\
\hline EFPI-GDP & RER & 0.424 & EFPI-GDP & RER & 0.419 & EFPI-GDP & RER & 0.973 \\
\hline EFPI-GDP & IBOV & 0.000 & EFPI-GDP & IBOV & 0.001 & EFPI-GDP & IBOV & 0.015 \\
\hline EFPI-GDP & ALL & 0.038 & EFPI-GDP & ALL & 0.058 & EFPI-GDP & ALL & 0.027 \\
\hline
\end{tabular}


Table 6: Point estimates of the Forecast Error Variance Decompositions, before and after the 2008 financial crisis

Note: This table presents the fraction of the s-step forecast-error variance of variable $\mathrm{i}$ that can be attributed to the $\mathrm{j}^{\text {th }}$ orthogonalized innovation. We show the FEVDs for the full period and also for the two sub-samples (before and after the 2008 financial crisis).

\begin{tabular}{|c|c|c|c|c|c|c|}
\hline Period & INVESTMENT & CRED-GDP & RIR & RER & IBOV & EFPI-GDP \\
\hline & \multicolumn{6}{|c|}{ Full period } \\
\hline 1 & 100 & 0.000 & 0.000 & 0.000 & 0.000 & 0.000 \\
\hline 2 & 98.22 & 0.096 & 0.488 & 0.055 & 0.222 & 0.918 \\
\hline 3 & 96.54 & 0.610 & 0.467 & 0.426 & 0.748 & 1.209 \\
\hline 4 & 94.21 & 0.630 & 1.150 & 0.673 & 1.481 & 1.859 \\
\hline 5 & 93.50 & 0.613 & 1.351 & 0.728 & 1.820 & 1.991 \\
\hline 6 & 93.44 & 0.612 & 1.347 & 0.723 & 1.890 & 1.984 \\
\hline 7 & 93.34 & 0.625 & 1.428 & 0.734 & 1.889 & 1.982 \\
\hline 8 & 93.27 & 0.628 & 1.486 & 0.737 & 1.891 & 1.988 \\
\hline 9 & 93.26 & 0.627 & 1.491 & 0.736 & 1.893 & 1.989 \\
\hline 10 & 93.26 & 0.628 & 1.493 & 0.737 & 1.893 & 1.989 \\
\hline 11 & 93.25 & 0.628 & 1.498 & 0.738 & 1.893 & 1.989 \\
\hline \multirow[t]{2}{*}{12} & 93.25 & 0.628 & 1.499 & 0.738 & 1.893 & 1.989 \\
\hline & \multicolumn{6}{|c|}{ Before crisis - $1996 m 3$ to $2008 \mathrm{m8}$} \\
\hline 1 & 100 & 0.000 & 0.000 & 0.000 & 0.000 & 0.000 \\
\hline 2 & 94.50 & 1.781 & 1.940 & 0.174 & 0.051 & 1.550 \\
\hline 3 & 92.08 & 3.885 & 1.835 & 0.523 & 0.125 & 1.553 \\
\hline 4 & 87.11 & 3.732 & 3.896 & 1.114 & 1.387 & 2.756 \\
\hline 5 & 85.04 & 3.642 & 4.282 & 1.721 & 2.312 & 2.999 \\
\hline 6 & 84.57 & 3.619 & 4.308 & 1.803 & 2.691 & 3.011 \\
\hline 7 & 84.32 & 3.613 & 4.408 & 1.831 & 2.807 & 3.026 \\
\hline 8 & 84.24 & 3.609 & 4.427 & 1.848 & 2.852 & 3.027 \\
\hline 9 & 84.22 & 3.610 & 4.426 & 1.849 & 2.864 & 3.028 \\
\hline 10 & 84.22 & 3.612 & 4.428 & 1.848 & 2.868 & 3.028 \\
\hline 11 & 84.21 & 3.612 & 4.428 & 1.848 & 2.869 & 3.028 \\
\hline \multirow[t]{2}{*}{12} & 84.21 & 3.612 & 4.429 & 1.848 & 2.869 & 3.028 \\
\hline & \multicolumn{6}{|c|}{ After crisis - 2008m12 to $2015 \mathrm{~m} 10$} \\
\hline 1 & 100 & 0.000 & 0.000 & 0.000 & 0.000 & 0.000 \\
\hline 2 & 86.19 & 4.250 & 3.229 & 3.261 & 3.071 & 0.004 \\
\hline 3 & 73.17 & 7.878 & 3.963 & 10.71 & 4.104 & 0.175 \\
\hline 4 & 70.39 & 7.854 & 3.934 & 13.47 & 3.789 & 0.561 \\
\hline 5 & 69.38 & 7.436 & 5.806 & 12.75 & 3.658 & 0.970 \\
\hline 6 & 68.04 & 7.265 & 6.695 & 13.24 & 3.575 & 1.191 \\
\hline 7 & 67.56 & 7.271 & 6.664 & 13.71 & 3.546 & 1.249 \\
\hline 8 & 67.53 & 7.252 & 6.724 & 13.67 & 3.534 & 1.288 \\
\hline 9 & 67.44 & 7.242 & 6.751 & 13.73 & 3.540 & 1.295 \\
\hline 10 & 67.39 & 7.245 & 6.760 & 13.77 & 3.547 & 1.295 \\
\hline 11 & 67.33 & 7.242 & 6.833 & 13.75 & 3.544 & 1.298 \\
\hline 12 & 67.29 & 7.236 & 6.860 & 13.76 & 3.542 & 1.302 \\
\hline
\end{tabular}


Figure 1: Brazilian Gross Fixed Capital Formation (quarterly) and our high-frequency investment estimate (monthly), 1996 to 2015

(a) Monthly vs Quarterly Investment

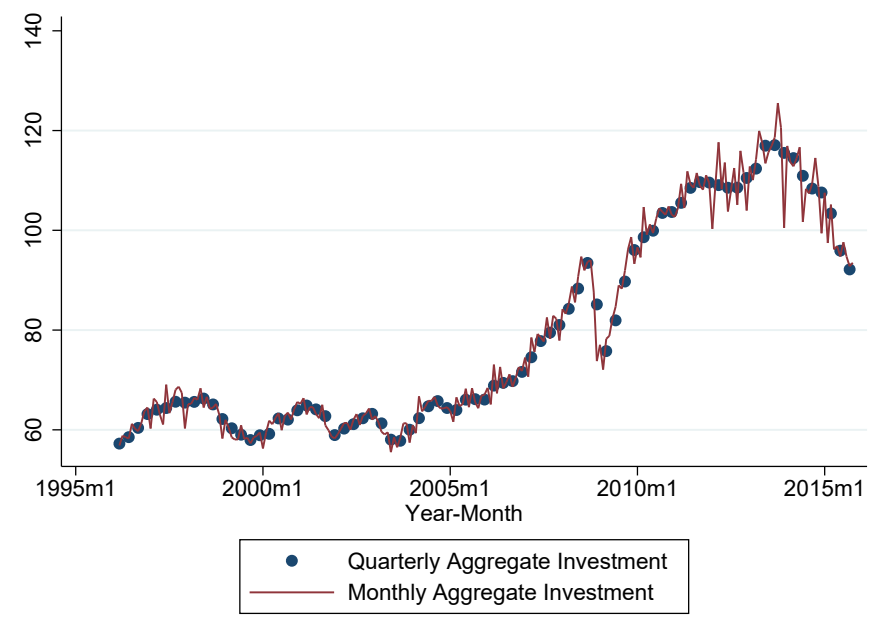

(b) Monthly vs Smoothed Monthly Investment

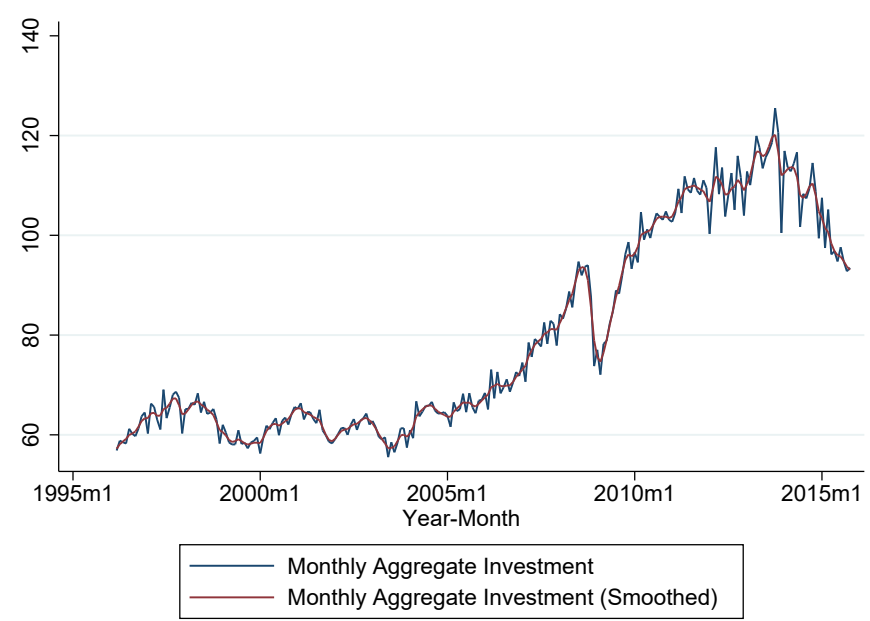

Note: (a) We compare the original seasonally-adjusted quarterly gross fixed capital formation of the Brazilian GDP (blue scatter) with the monthly gross fixed capital formation estimated with the Denton Proportional Method (solid red line), using a high-frequency series composed by the production of construction inputs and production of capital goods.

(b)We use the Hodrick-Prescott high-pass filter to separate the monthly investment series into trend and cycle components, with the smoothing parameter $\lambda=1$. We then use the trend component of the series (solid red line) as a smoothed version of the original monthly investment series (solid blue line). 
Figure 2: IRF estimates for the whole period (1996m3 - 2015m10)

Note: This figure reports the Impulse Response Functions (IRFs) of a one percent shock in all endogenous variables in the system and its impact on aggregate investment. We report the point estimates with one asymptotic standard error band for each impulse response over the horizon of fifteen months. Graphics are in the following order: $\triangle I N V E S T M E N T, \triangle C R E D I T-G D P$, $\triangle R I R, \triangle R E R, \triangle I B O V$, and EFPI-GDP.

(a) Response of Investment to Investment tio

(b) Response of Investment to Credit-GDP ra-
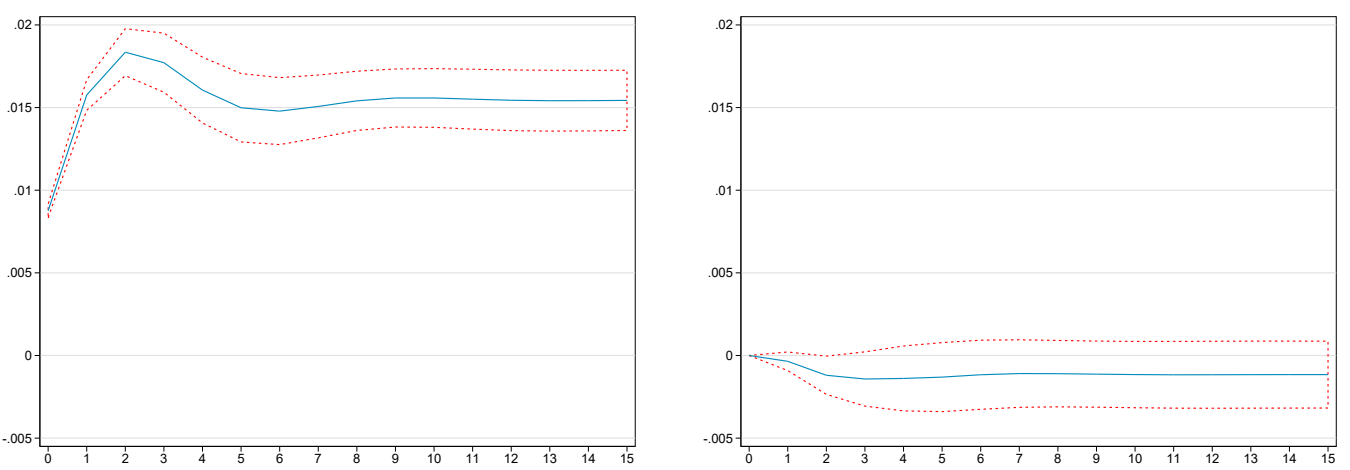

(c) Response of Investment to Real Interest(d) Response of Investment to Real Exchange Rate

Rate
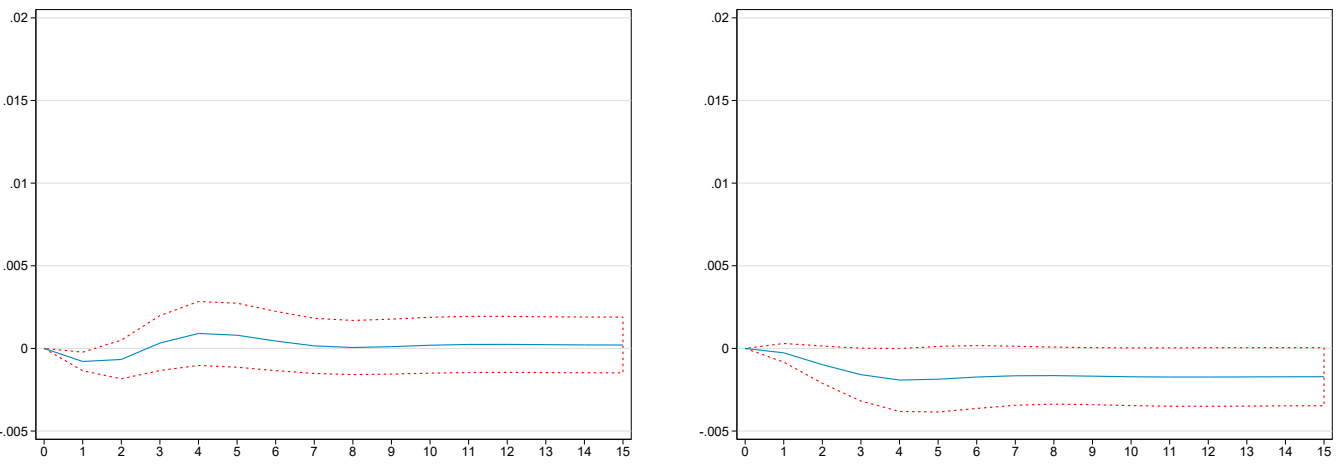

(e) Response of Investment to Ibovespa

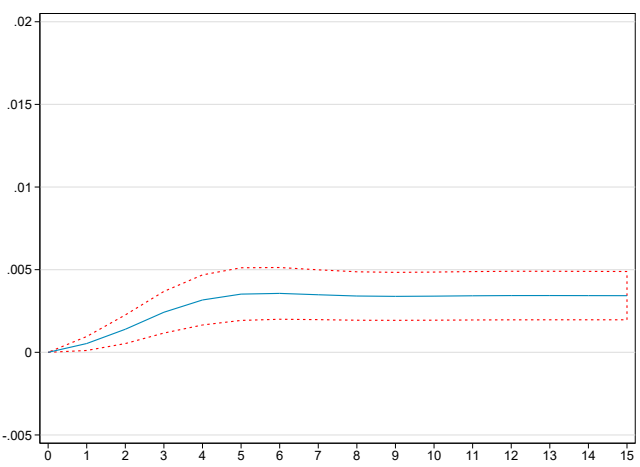

(f) Response of Investment to Equity Foreign Capital Investment/GDP

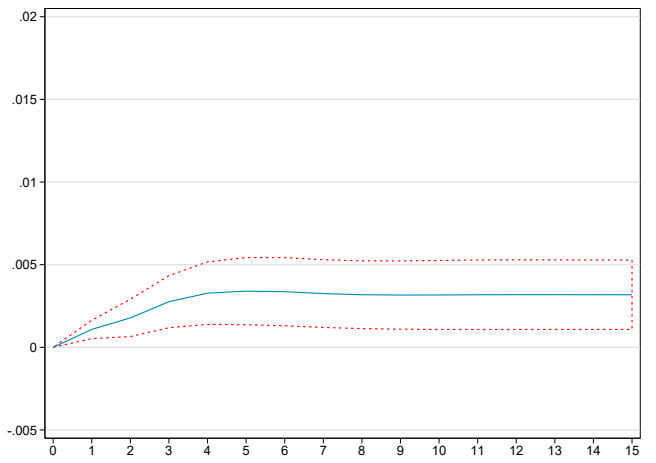


Figure 3: IRFs estimates, before and after the 2008 financial crisis

Note: This figure reports the Impulse Response Functions (IRFs) of a one percent shock in all endogenous variables in the system and its impact on aggregate investment. We report the point estimates with one asymptotic standard error band for each impulse response over the horizon of fifteen months. Graphics are in the following order for both panels (a) and (b): $\triangle I N V E S T M E N T, \triangle C R E D I T-G D P, \triangle R I R, \triangle R E R, \triangle I B O V$, and EFPI-GDP.

(a) Before the 2008 Financial Crisis $(1996 \mathrm{~m} 3-2008 \mathrm{~m} 8$ )
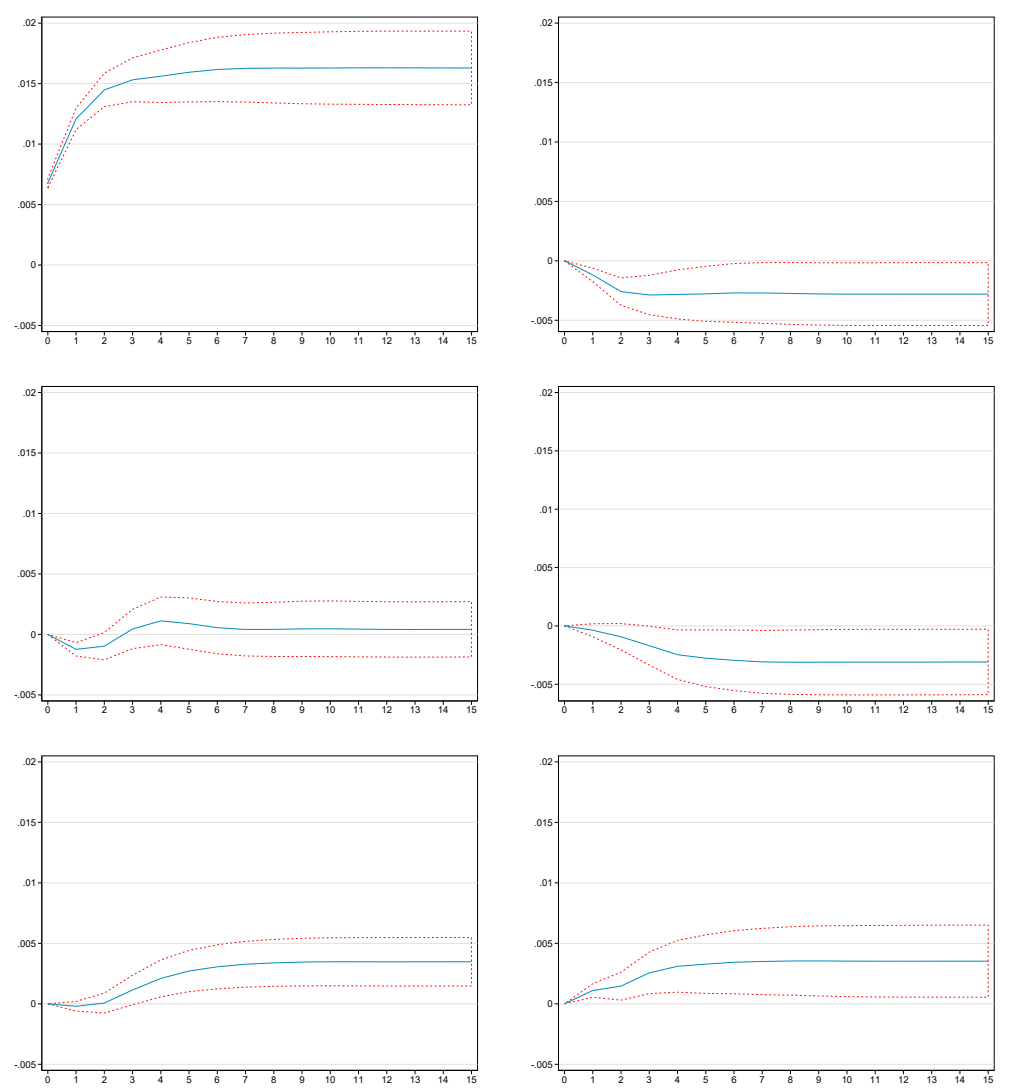

(b) After the 2008 Financial Crisis (2008m12 - 2015m10)
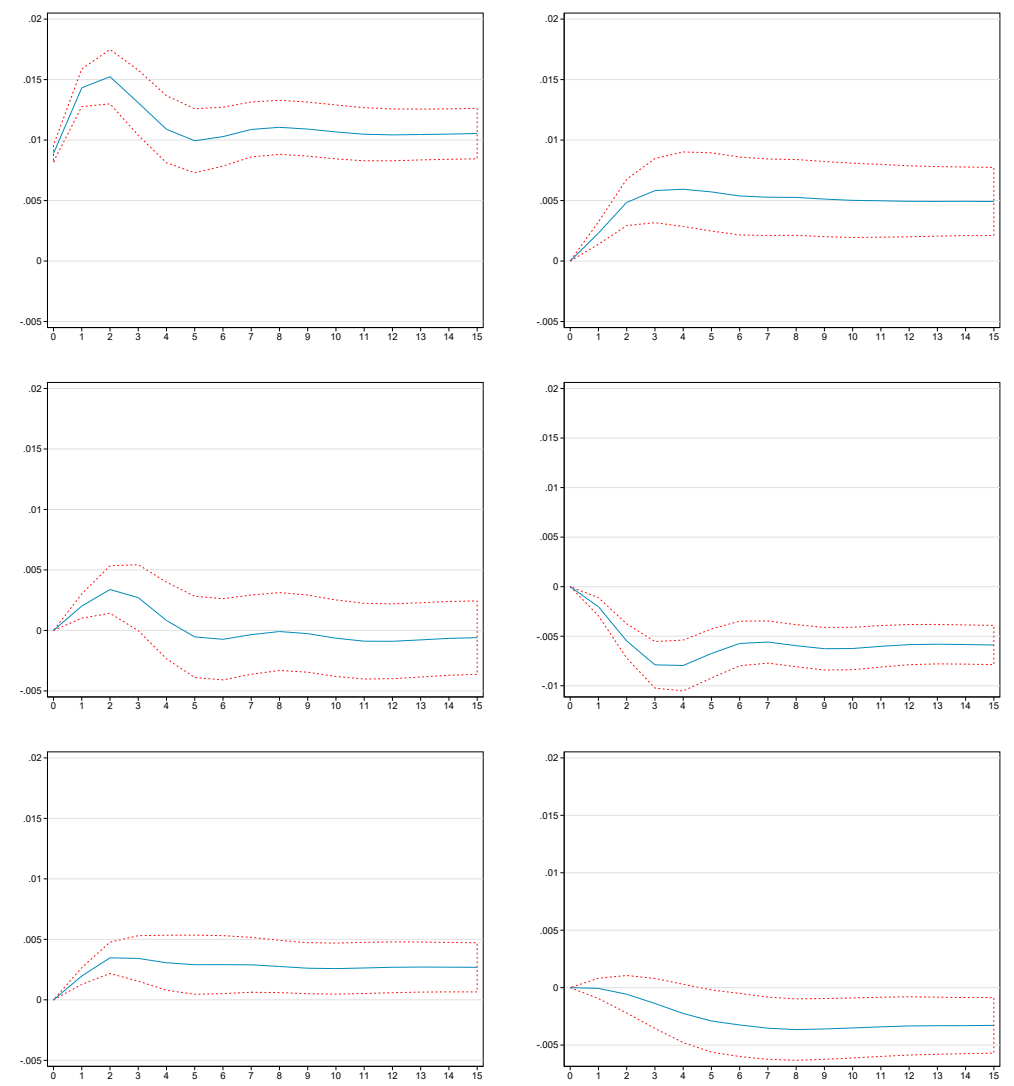
Figure 4: Robustness check: COIRFs with alternative variables ordering - Full Period

(a) Order \#1

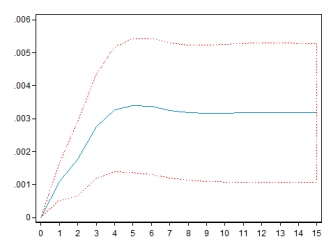

(e) Order \#5

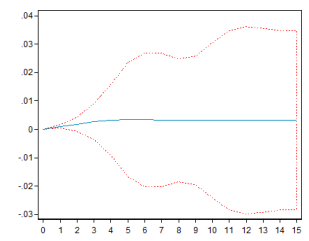

(i) Order $\# 9$

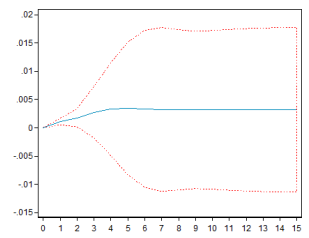

(m) Order \#13

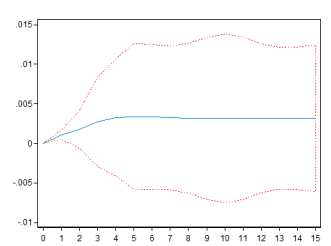

(q) Order \#17

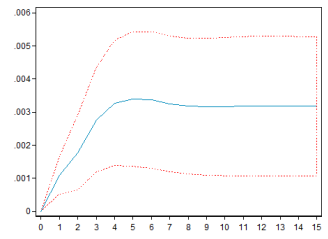

(u) Order \#21

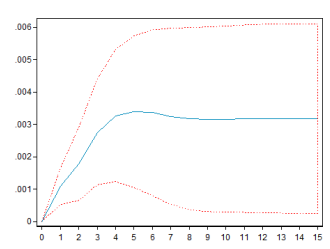

(b) Order \#2

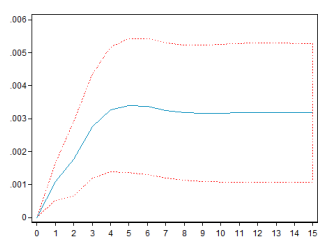

(f) Order \#6

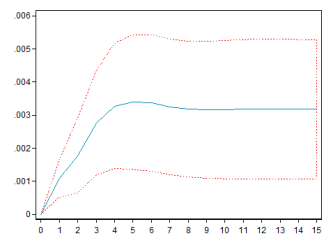

(j) Order \#10

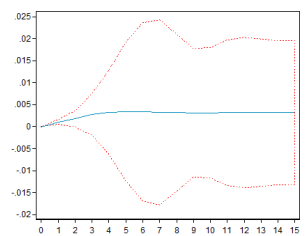

(n) Order \#14

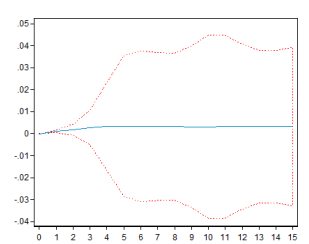

(r) Order \#18

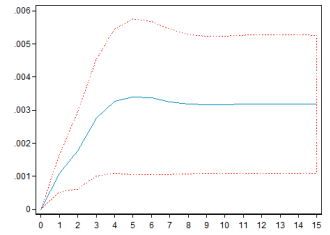

(v) Order \#22

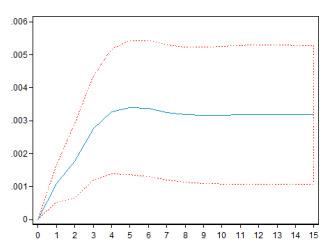

(c) Order \#3

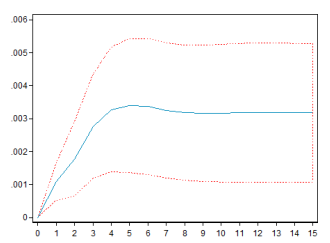

(g) Order \#7

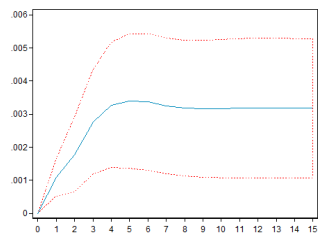

(k) Order \#11

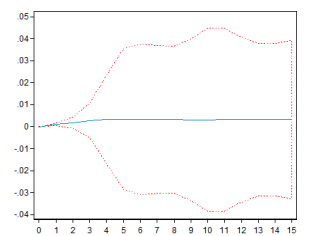

(o) Order \#15

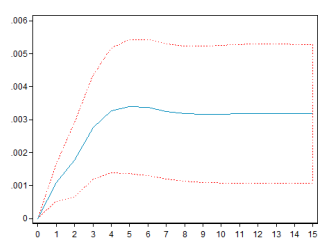

(s) Order \#19

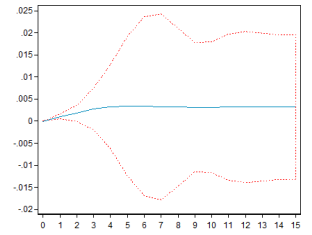

(w) Order \#23

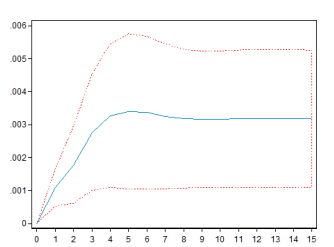

(d) Order \#4

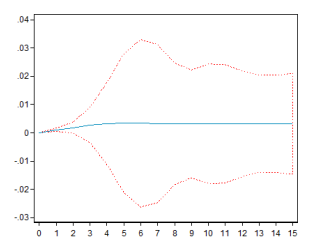

(h) Order \#8

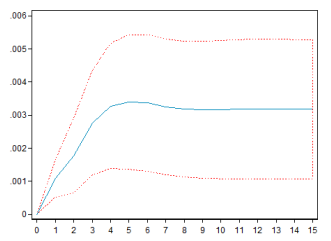

(l) Order \#12

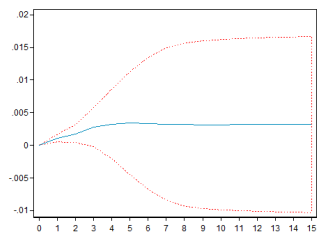

(p) Order \#16

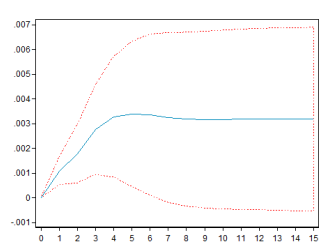

(t) Order \#20

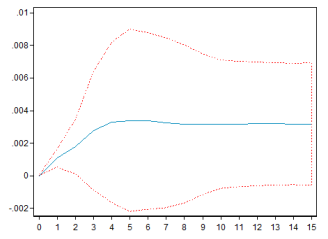

(x) Order \#24

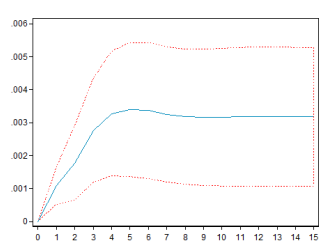


Figure 5: The effect of the Equity Foreign Portfolio Investment on Investment and Structural change in subsidised credit, before and after the 2008 financial crisis

(a) Response of Investment to a shock in EFPI - Before and After the crisis

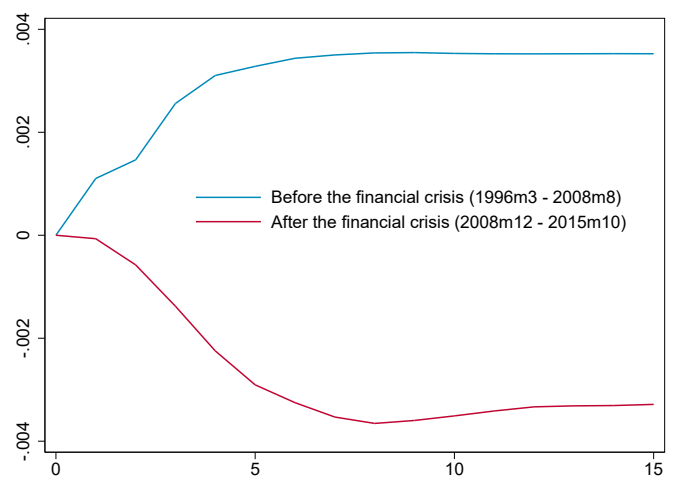

(b) Transfers from Brazilian National Treasury to Public Banks (\% of GDP)

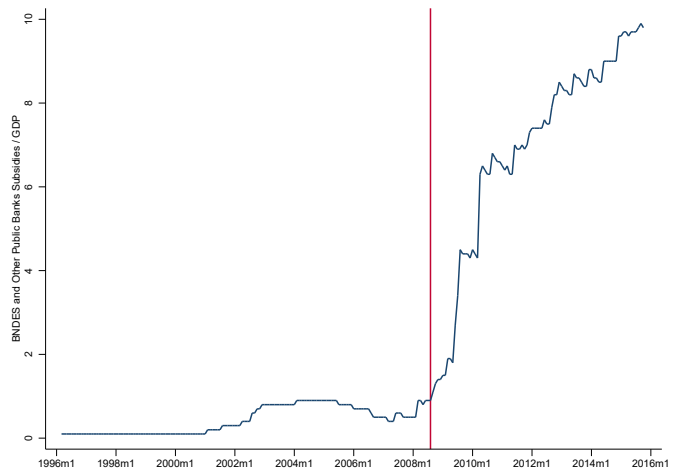

Figure 6: Government Stability Index - Brazil (ICRG, 2014-2015)

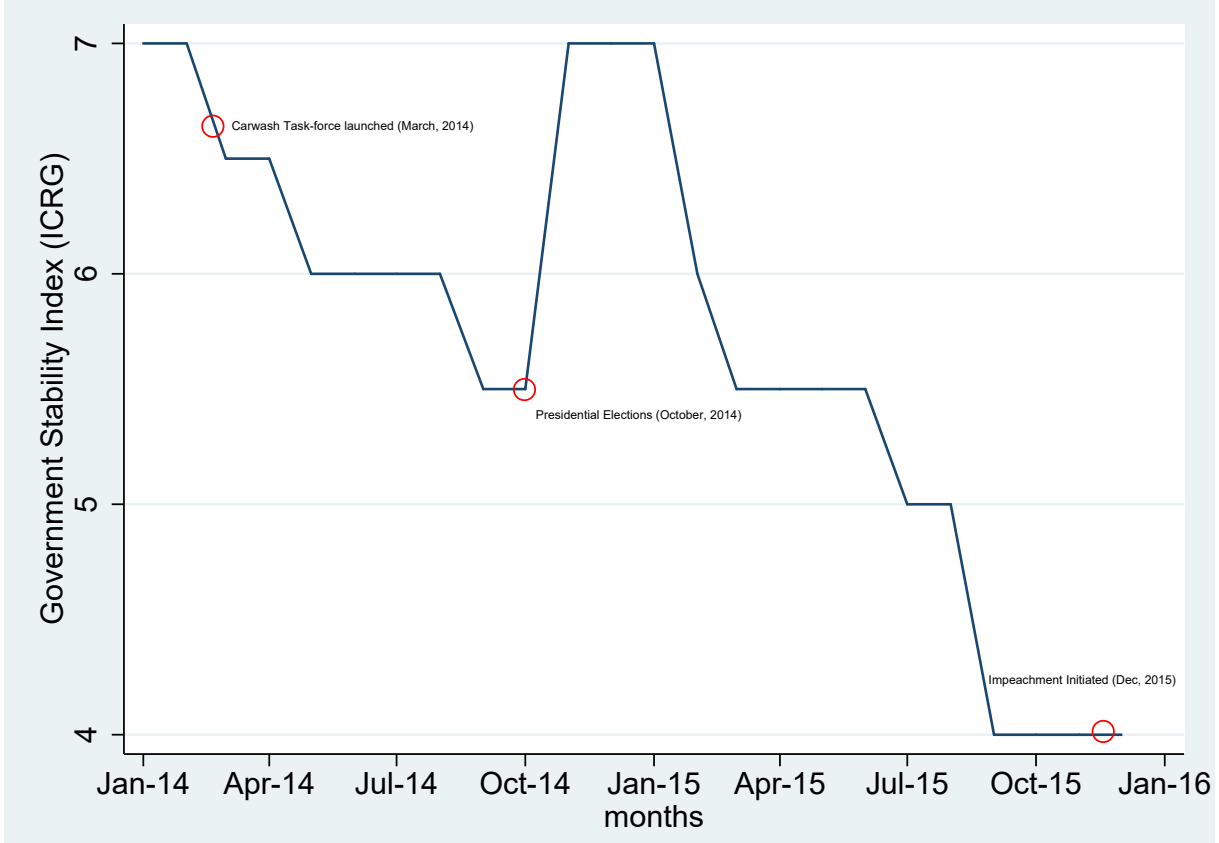


Figure 7: Net flows of Foreign Capitals to Brazil (inflows minus outflows), as a ratio of GDP, 1996 to 2017

(a) Foreign Direct, Portfolio and Other Investment

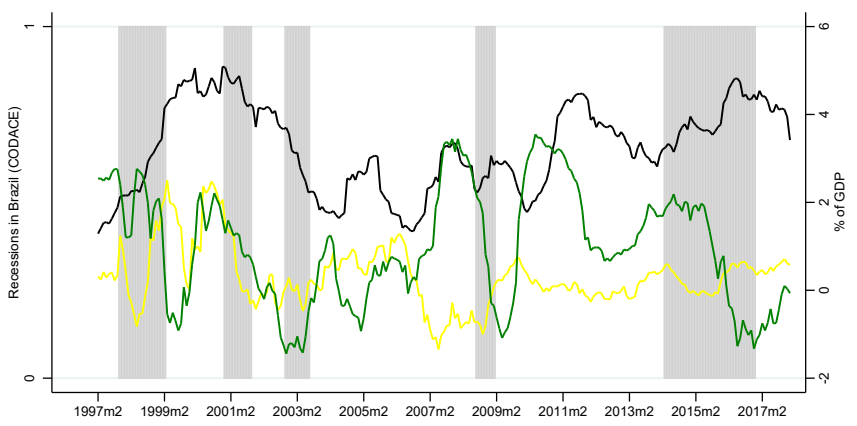

$$
\begin{array}{ll}
-\quad \text { Foreign Direct Investment - Total - Net (\% of GDP) } \\
\text { — } & \text { Foreign Portfolio Flows - Total - Net (\% of GDP) } \\
\text { Other Investment - Total - Net (\% of GDP) } \\
\text { Recessions in Brazil (CODACE) }
\end{array}
$$

(b) Foreign Portfolio Investment - Equity vs Debt Securities

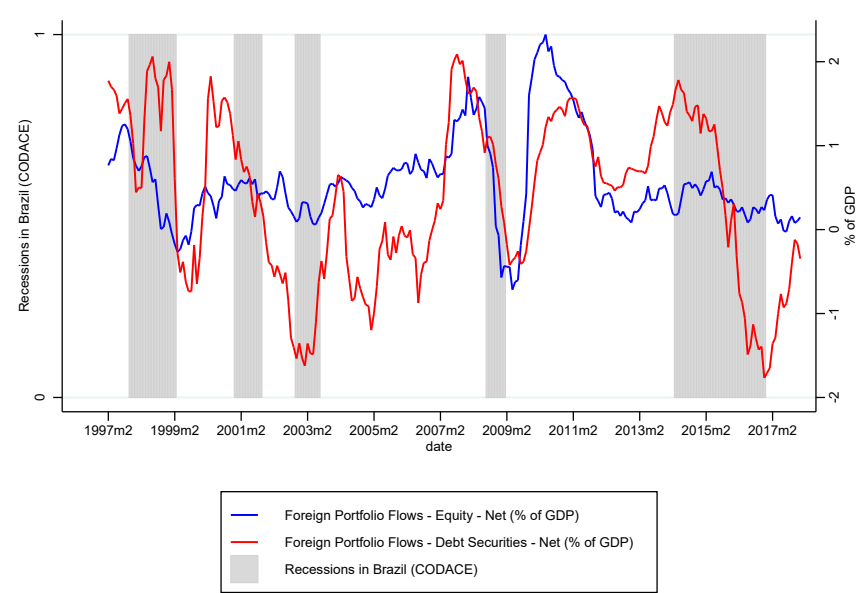

Note: Net flows refers to inflows minus outflows of foreign capitals (net incurrence of liabilities). Data comes from Central Bank of Brazil, Balance of Payments - BPM6, Monthly Series. 


\section{Appendix A: Graphics of Variables}

Figure 8: Graphic of variables expressed in levels, together with the monthly investment, 1996m3 to $2015 \mathrm{~m} 10$

(a) Investment vs Credit-to-GDP

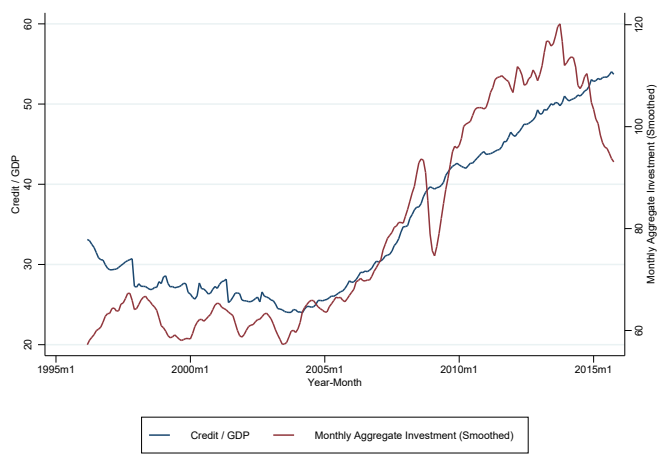

(c) Investment vs Real Exchange Rate

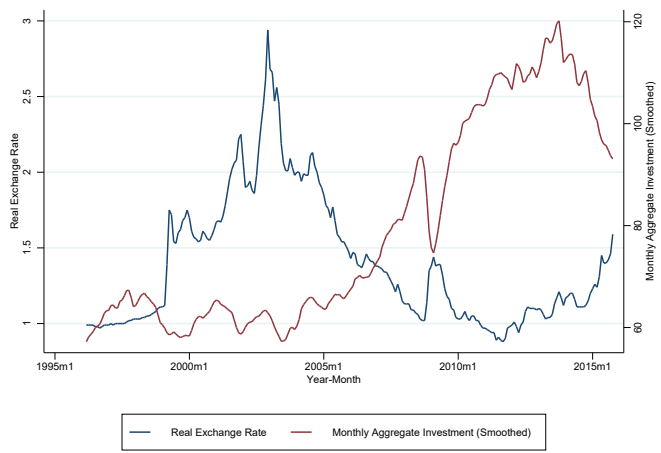

(e) Investment vs Net Foreign Portfolio Flows

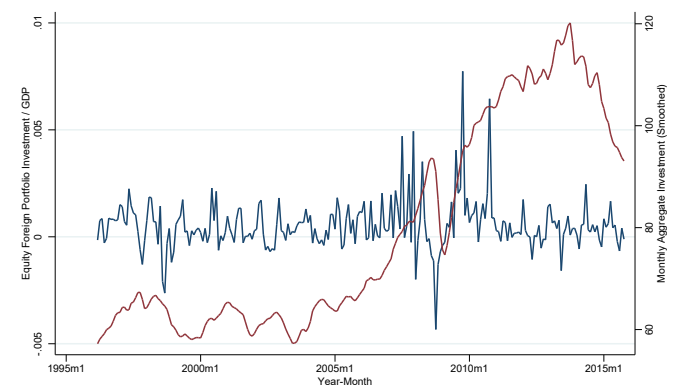

- Equily Forelign Portrolio Investment/ GDP $\quad-$ Monhthy A Agregate Investment (Smoothed)

(g) Investment vs MSCI World

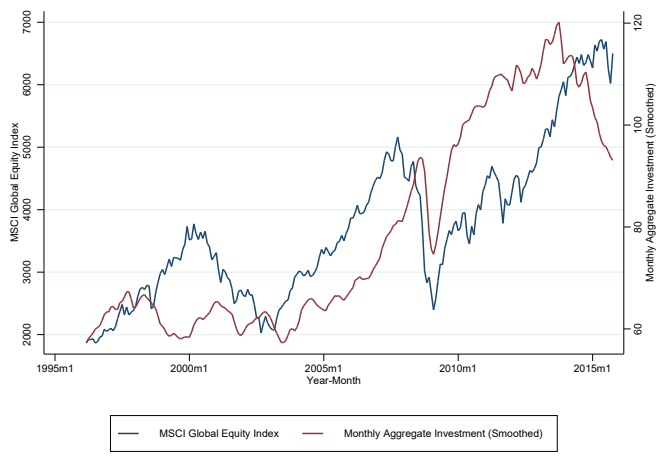

(b) Investment vs Real Interest Rate

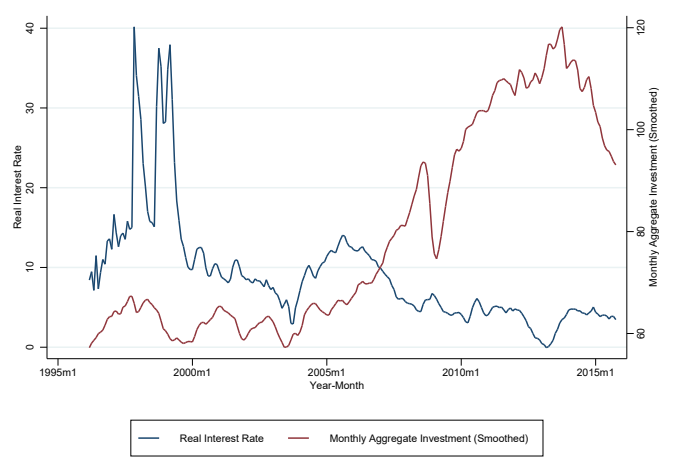

(d) Investment vs Ibovespa

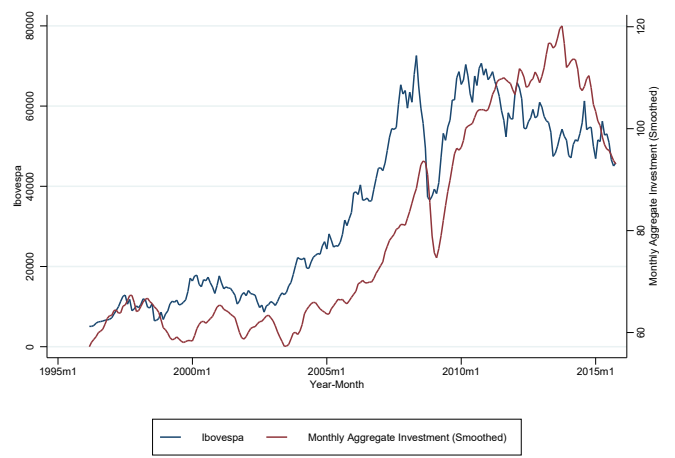

(f) Investment vs Commodity Prices

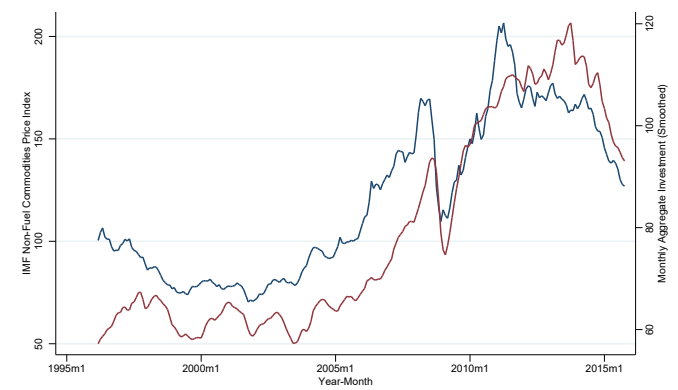

- IMF Non-Fuel Commodities Price Indiex $\quad-\quad$ Monhty Aggregate IIvestment (Smoothed)

(h) Investment vs Economic Recessions

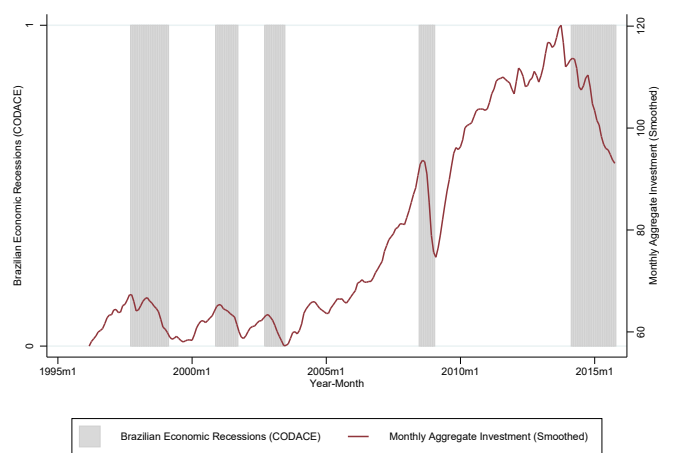


Figure 9: Graphic of stationary variables, together with the monthly investment, $1996 \mathrm{~m} 3$ to $2015 \mathrm{~m} 10$

(a) Investment vs Credit-to-GDP

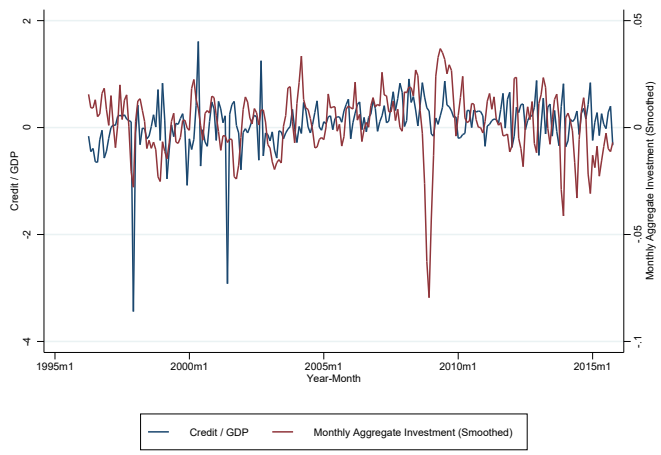

(c) Investment vs Real Exchange Rate

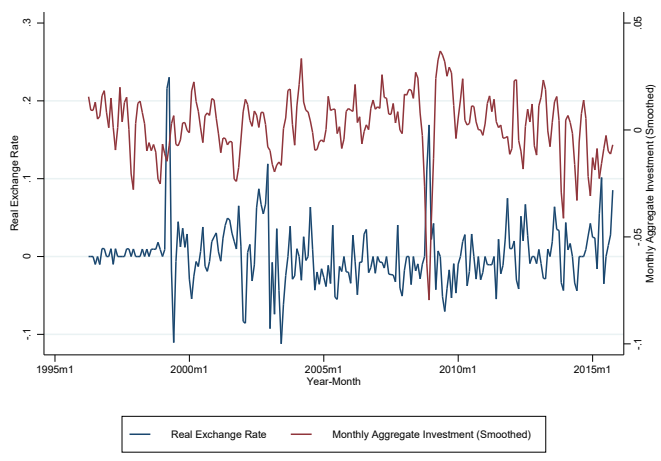

(e) Investment vs Net Foreign Portfolio Flows

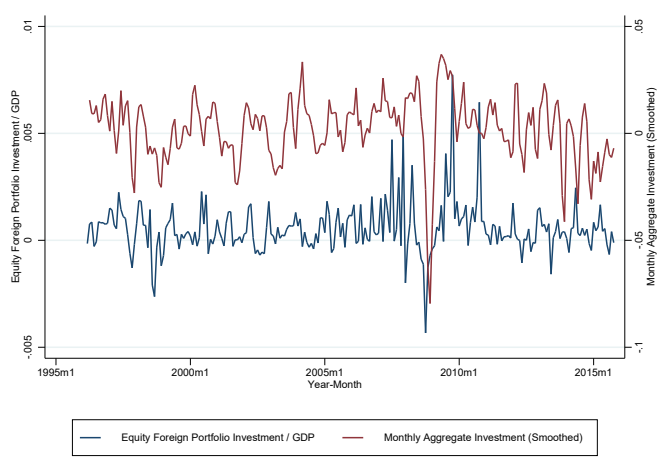

(g) Investment vs MSCI World

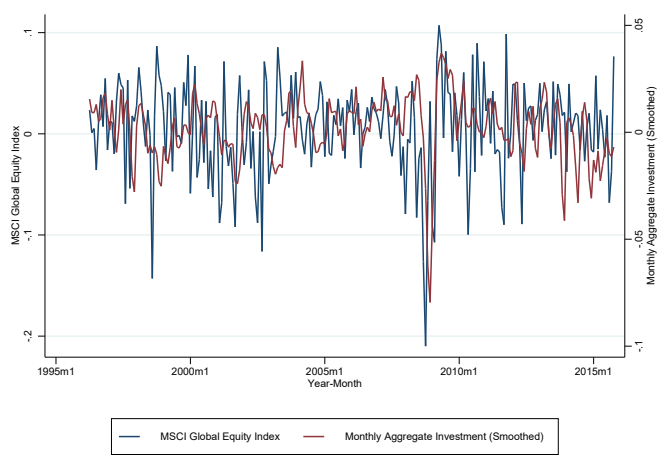

(b) Investment vs Real Interest Rate

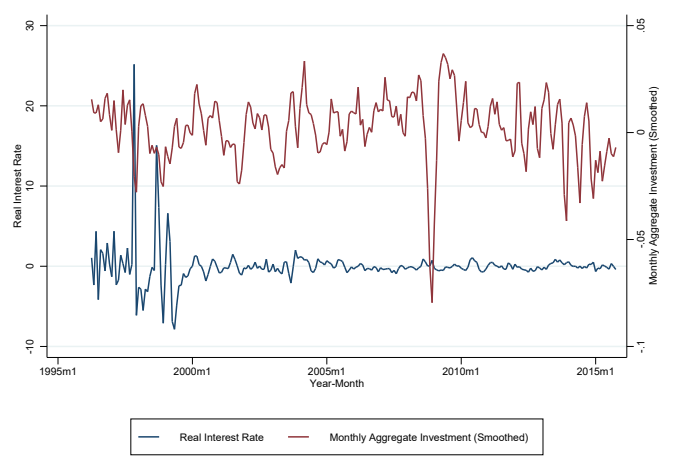

(d) Investment vs Ibovespa

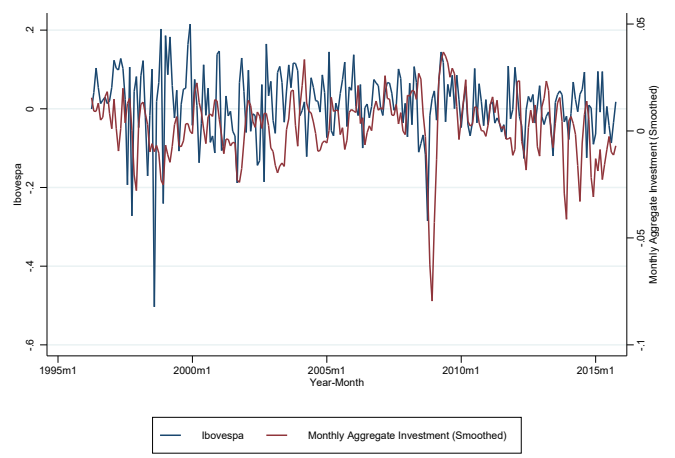

(f) Investment vs Commodity Prices

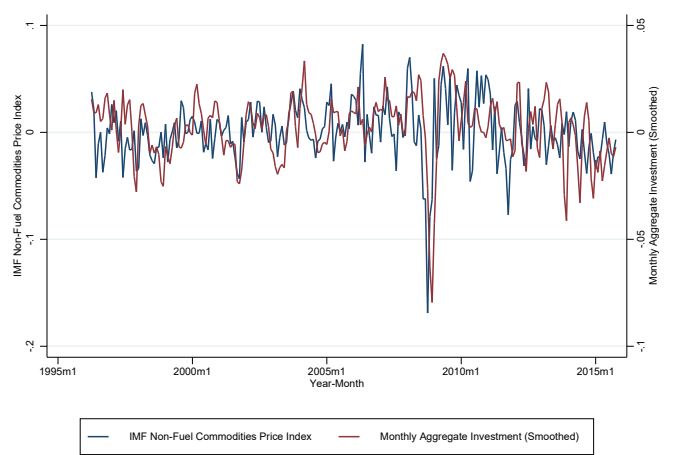

(h) Investment vs Brazilian Economic Recessions

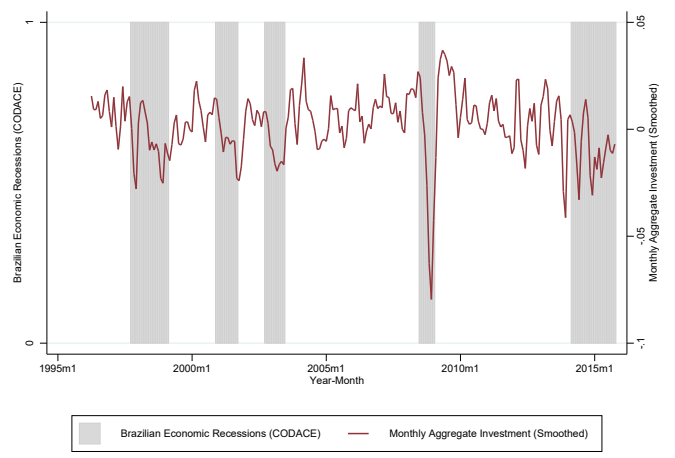




\section{Appendix B: Statistical tests}

\section{Stationary tests}

Stationarity is a key assumption for most of time series models. In this paper, we use three tests to assess if a given series is plausible stationary: Augmented Dickey Fuller (ADF), Phillips-Perron (PP), and Kwiatkowski-Phillips-Schmidt-Shin (KPSS). The results of these tests (ADF, PP and KPSS) are shown in Table 7.

Using a $5 \%$ critical value cutoff, we find that most of our continuous variables are non-stationary in level, but they are stationary in first difference (i.e., they are I(1)). The exception is our measure of net foreign capital flows (EFPI-GDP), which is $\mathrm{I}(0)$. We also run some different specification tests and lag choosing $^{20}$, but the results hold for all series. We henceforth log-differentiate most of our variables - we use the " $\Delta$ " symbol to refer to them -, except for EFPI-GDP and our dummy variables (2008CRISIS and RECESSION), which are already stationary in levels.

\footnotetext{
${ }^{20}$ We choose the optimum lag for the unit root tests based on the Akaike Information Criteria (AIC), being twelve the maximum allowed lag.
} 
Table 7: Stationarity and Unit Root Testing

Note: $C=$ constant, $T=$ trend. Our pre-estimation tests include lags 1 to 14 , and we use the Akaike Information Criteria (AIC) to choose the appropriate model (optimal lag). We show results for the variables expressed in levels and for the optimum lag only (different lags result in the same conclusions). The null hypothesis behind Augmented Dickey-Fuller (ADF) and Phillips-Perron (PP) tests is that the variable contains a unit root - rejecting the null hypothesis means that a stationary process generated the variable. Conversely, the Kwiatkowski-Phillips-Schmidt-Shin (KPSS) test assumes the null hypothesis of stationarity.

\begin{tabular}{|c|c|c|c|c|c|c|c|c|c|c|}
\hline \multirow[b]{2}{*}{ Variable } & \multicolumn{3}{|c|}{ Augmented Dickey-Fuller (ADF) } & \multicolumn{3}{|c|}{ Phillips-Perron } & \multicolumn{3}{|c|}{ KPSS Test } & \multirow{2}{*}{$\begin{array}{c}\text { Final Assessment } \\
\text { Order of } \\
\text { Integration }\end{array}$} \\
\hline & Model & $\begin{array}{l}\text { Tau Test } \\
\text { Statistic }\end{array}$ & $\begin{array}{c}\text { critical value } \\
(\text { at } 5 \%)\end{array}$ & Model & $\begin{array}{l}\text { Tau Test } \\
\text { Statistic }\end{array}$ & $\begin{array}{c}\text { critical value } \\
\text { (at } 5 \%)\end{array}$ & Model & $\begin{array}{l}\text { Tau Test } \\
\text { Statistic }\end{array}$ & $\begin{array}{c}\text { critical value } \\
\text { (at } 5 \%)\end{array}$ & \\
\hline \multirow{2}{*}{ Investment } & $\mathrm{C}$ & $-1,033$ & $-2,881$ & $\mathrm{C}$ & $-1,023$ & $-2,881$ & $\mathrm{C}$ & 1,810 & 0,463 & \multirow{2}{*}{$I(1)$} \\
\hline & $\mathrm{C}, \mathrm{T}$ & $-1,564$ & $-3,432$ & $\mathrm{C}, \mathrm{T}$ & $-1,210$ & $-3,432$ & $\mathrm{C}, \mathrm{T}$ & 0,327 & 0,146 & \\
\hline \multirow{2}{*}{ CRED-GDP } & $\mathrm{C}$ & 1, 934 & $-2,881$ & $\mathrm{C}$ & 2,085 & $-2,881$ & $\mathrm{C}$ & 1,690 & 0,463 & \multirow{2}{*}{$I(1)$} \\
\hline & $\mathrm{C}, \mathrm{T}$ & $-2,730$ & $-3,432$ & $\mathrm{C}, \mathrm{T}$ & $-2,766$ & $-3,432$ & $\mathrm{C}, \mathrm{T}$ & 1,830 & 0,146 & \\
\hline \multirow{2}{*}{ RIR } & $\mathrm{C}$ & $-2,653$ & $-2,881$ & $\mathrm{C}$ & $-2,797$ & $-2,881$ & $\mathrm{C}$ & 1,190 & 0,463 & \multirow{2}{*}{$I(1)$} \\
\hline & $\mathrm{C}, \mathrm{T}$ & $-4,146$ & $-3,432$ & $\mathrm{C}, \mathrm{T}$ & $-4,133$ & $-3,432$ & $\mathrm{C}, \mathrm{T}$ & 0,082 & 0,146 & \\
\hline \multirow{2}{*}{ RER } & $\mathrm{C}$ & $-1,728$ & $-2,881$ & $\mathrm{C}$ & $-1,615$ & $-2,881$ & $\mathrm{C}$ & 0,537 & 0,463 & \multirow{2}{*}{$I(1)$} \\
\hline & $\mathrm{C}, \mathrm{T}$ & $-1,881$ & $-3,432$ & $\mathrm{C}, \mathrm{T}$ & $-1,770$ & $-3,432$ & $\mathrm{C}, \mathrm{T}$ & 0,313 & 0,146 & \\
\hline \multirow{2}{*}{ IBOV } & $\mathrm{C}$ & $-1,447$ & $-2,881$ & $\mathrm{C}$ & $-1,403$ & $-2,881$ & $\mathrm{C}$ & 1,800 & 0,463 & \multirow{2}{*}{$I(1)$} \\
\hline & $\mathrm{C}, \mathrm{T}$ & $-1,863$ & $-3,432$ & $\mathrm{C}, \mathrm{T}$ & $-1,688$ & $-3,432$ & $\mathrm{C}, \mathrm{T}$ & 0,222 & 0,146 & \\
\hline \multirow{2}{*}{ IEFPI-GDP } & $\mathrm{C}$ & $-6,796$ & $-2,881$ & $\mathrm{C}$ & $-12,85$ & $-2,881$ & $\mathrm{C}$ & 0,114 & 0,463 & \multirow{2}{*}{$I(0)$} \\
\hline & $\mathrm{C}, \mathrm{T}$ & $-6,784$ & $-3,432$ & $\mathrm{C}, \mathrm{T}$ & $-12,82$ & $-3,432$ & $\mathrm{C}, \mathrm{T}$ & 0,117 & 0,146 & \\
\hline \multirow{2}{*}{ COMM } & $\mathrm{C}$ & $-1,336$ & $-2,881$ & $\mathrm{C}$ & $-1,089$ & $-2,881$ & $\mathrm{C}$ & 1,640 & 0,463 & \multirow{2}{*}{$I(1)$} \\
\hline & $\mathrm{C}, \mathrm{T}$ & $-2,367$ & $-3,432$ & $\mathrm{C}, \mathrm{T}$ & $-1,564$ & $-3,432$ & $\mathrm{C}, \mathrm{T}$ & 0,216 & 0,146 & \\
\hline \multirow{2}{*}{ MSCI-WD } & $\mathrm{C}$ & $-0,370$ & $-2,881$ & $\mathrm{C}$ & $-0,390$ & $-2,881$ & $\mathrm{C}$ & 1,520 & 0,463 & \multirow{2}{*}{$I(1)$} \\
\hline & $\mathrm{C}, \mathrm{T}$ & $-1,669$ & $-3,432$ & $\mathrm{C}, \mathrm{T}$ & $-1,682$ & $-3,432$ & $\mathrm{C}, \mathrm{T}$ & 0,165 & 0,146 & \\
\hline
\end{tabular}


Exogeneity and marginal significance of variables

To complement the endogenous variables defined in the VAR system, we add variables that are plausibly exogenous to our model, i.e., variables that represent external conditions or the global business cycle, and probably are not (at least largely) affected by the Brazilian economy's behavior. Our motivation is based on the perception that external conditions, such as global liquidity, uncertainty, and the global business cycle may affect capital inflows to emerging markets, which is supported by the empirical evidence that point out global factors as crucial determinants of capital inflows (e.g., Calvo et al. (1996)).

Specifically, we consider the MSCI World Index as a proxy for the world equity market performance. We also add the Fed Funds rate as a proxy for the "flight-to-quality" movement of international investors, and we expect the opportunity cost of investing in emerging markets to be negatively related with capital inflows to Brazil. Because of the impact on terms-of-trade, we also consider the IMF Primary Commodity Prices index (ex-fuel, which is fairly approximated to Brazilian net exporting ${ }^{21}$ ) to capture the termsof-trade shocks to the local economy. Finally, we consider the monthly chronology of recessions in the Brazilian economy dated by the Business Cycles Dating Committee (CODACE), that accounts for different economic regimes in the business cycle. Finally, we test the jointly significance of the coefficients of these variables in our $\mathrm{k}=6$ equations in the unrestricted VARX system (Table 8). As parsimony is a key feature here, we keep only those exogenous variables which are marginally significant in our models - we consider a $0.1 p$-value threshold to determine whether a given variable should be included or not in the estimated model.

Table 8: Joint test of significance of the exogenous variables' coefficients

Note: This table reports the test statistics of the marginal significance of each exogenous variable in the estimated VARX system. Prob $>$ Chi2 reveals the p-value associated with the null hypothesis that all lags of the exogenous variables are equal to zero in all system's equations.

\begin{tabular}{lcc}
\hline Variable & $\chi^{2}$ & Prob $>\chi^{2}$ \\
\hline L2. $\Delta$ COMM & 10.89 & 0.0920 \\
$\Delta$ MSCI-WD & 209.69 & 0.0000 \\
$\Delta$ FED-FUNDS & 1.81 & 0.9367 \\
$\Delta$ US10YBOND & 2.68 & 0.8483 \\
2008CRISIS & 11.76 & 0.0676 \\
RECESSION_DUM & 28.87 & 0.0001 \\
\hline
\end{tabular}

Complementing our analysis of variables that are potentially being determined outside the model, we also perform some bivariate Granger Causality Tests to check if the lags of our dependent variable (investment) do not help to explain current values of the exogenous variables. Indeed, most of these variables representing external conditions help to explain the endogenous variable meanwhile they are

\footnotetext{
${ }^{21}$ Brazil's main exports include soybeans, coffee, tobacco, cocoa, beef, poultry, orange juice, raw cane and refined sugar, iron ore and concentrates, oilseed, and mineral fuels.
} 
not affected by the dependent variable (there is a unidirectional Granger-Causality from exogenous to endogenous variables). For this reason, we keep in the model only the plausibly exogenous variables that are marginally significant in our models and are not Granger-caused by the endogenous variables. ${ }^{22}$

Table 9: Table: LM test for residual autocorrelation in the model

\begin{abstract}
Note: This table reports the statistics of the LM test for residual autocorrelation after the VAR. In the first model (A), maximum lag is set to be equal to the optimal lag-length suggested by the Akaike Information Criteria (AIC). Since there is evidence of autocorrelation in at least one lag $(p<0.10)$, we test in the second model $(\mathrm{B})$ the same specification with one extra lag for all endogenous variables (INVESTMENT, CRED-GDP, RIR, RER, IBOV, and EFPI). Prob $>\chi^{2}$ reveals the probability of rejecting the null hypothesis that there is no residual autocorrelation in that specific lag. The test statistics of the marginal significance of each exogenous variable in the estimated VAR system. Prob $>\chi^{2}$ reveals the p-value associated with the null hypothesis that all lags of the exogenous variables are jointly equal to zero.
\end{abstract}

\begin{tabular}{|c|c|c|c|}
\hline \multicolumn{4}{|c|}{ A) Maximum Lag $=2$} \\
\hline Lag & $\chi^{2}$ & $\mathrm{DF}$ & Prob $>\chi^{2}$ \\
\hline 1 & 48.7194 & 36 & 0.07659 \\
\hline 2 & 47.6566 & 36 & 0.09256 \\
\hline 3 & 34.8732 & 36 & 0.52206 \\
\hline \multicolumn{4}{|c|}{ B) Maximum Lag $=3$} \\
\hline Lag & $\chi^{2}$ & $\mathrm{DF}$ & Prob $>\chi^{2}$ \\
\hline 1 & 37.7648 & 36 & 0.38858 \\
\hline 2 & 40.1045 & 36 & 0.29308 \\
\hline 3 & 33.6176 & 36 & 0.58242 \\
\hline
\end{tabular}

Lag selection and residual autocorrelation

We use information criteria to define the lag-length of our VAR models. Simulations show that for monthly VAR models, the AIC tends to produce the most accurate impulse response estimates independent of the sample size (Ivanov \& Kilian, 2005). For that reason, we choose the AIC criterion instead of the HQIC, SBIC or other available lag-length selection criteria. Because our data is monthly, we set the maximum lag-length to twelve and check the AIC results for all different lag-lengths, trying to find the minimum AIC value. Both the $\mathrm{AIC}$ and Final Prediction Error (FPE) suggest that the optimum lag is equal to two, while HQIC and SBIC recommended lag equal to one.

Following the optimum lag choice $\left(p^{*}=2\right.$ as suggested by AIC), we proceed to a model checking of its adequacy (Luetkepohl, 2011). Because residual autocorrelation may lead to inefficient coefficient estimations using OLS, we perform the Breusch-Godfrey Lagrange Multiplier (LM) test to check if the residuals are white noise, i.e., if they have zero mean and constant variance. According to Luetkepohl (2011), this test is recommended for low order autocorrelation, instead of the Portmanteau test, which

\footnotetext{
${ }^{22}$ The exception is the 2008CRISIS dummy. Although this variable is marginally significant in the model (see Table 8), its periods coincide with the 2008-2009 economic recession in Brazil dated by CODACE, which is already included in the model. Moreover, since we split our sample in before and after the 2008 financial crisis, the 2008CRISIS dummy would be naturally out of the model in all tests using these sub-samples.
} 
is recommended for high-order correlation. Specifically, the LM test for residual autocorrelation is a test for zero coefficient matrices for the residuals,

$$
u_{t}=B_{1} u_{t-1}+\ldots+B_{h} u_{t-h}+e_{t}
$$

under the null hypothesis that all coefficients of the past errors are jointly equal to zero. We test:

$$
H_{0}: B_{1}=\ldots=B_{h}=0 \text { versus } H_{1}: B_{i} \neq 0 \text { for at least one } i \in 1, \ldots, h \text {. }
$$

As one could note from Table 9, the LM test suggests that there is a significant residual autocorrelation at the optimal lag-length suggested by AIC (maximum lag=2), so we add one more lag and test for residual autocorrelation again. Table 9 reveals that we end up getting white noise residuals in the model with $\operatorname{lag}^{*}=3$. Using this rule of thumb, the model with lag $=3$ is sufficient to eliminate the autocorrelation of the residuals, at the same time that the model does not become overparameterized. Therefore, we use three lags of each endogenous variables to estimate our VARX systems.

\section{Model Stability}

One of the critical assumptions for generating IRFs is that the VAR must be stable (Baum, 2013). The stability of the system is complementary to the assumption of covariance stationarity for the variables, i.e., that variables should have a constant mean and a constant variance. If the model is stable, it has an infinite-order vector moving-average representation, and thus impulse-response functions and forecasterror variance decompositions have known interpretations (Stata et al., 2015). Figure 10 resumes the stability analysis for the full period (a), and also for the sub-samples before (b) and after the 2008 financial crisis (c).

Figure 10: Stability of the VARX System - Full period and before/after the 2008 financial crisis

(a) Full period $(1996 \mathrm{~m} 3-2015 \mathrm{~m} 10)$

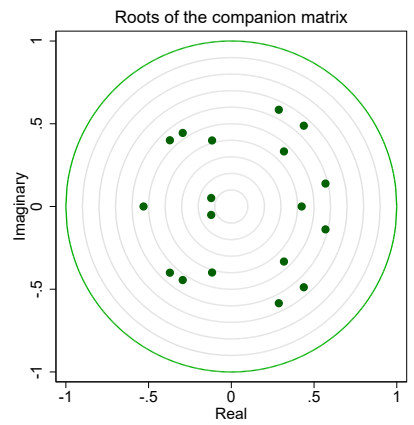

(b) Before crisis (1996m3 - 2008m8)

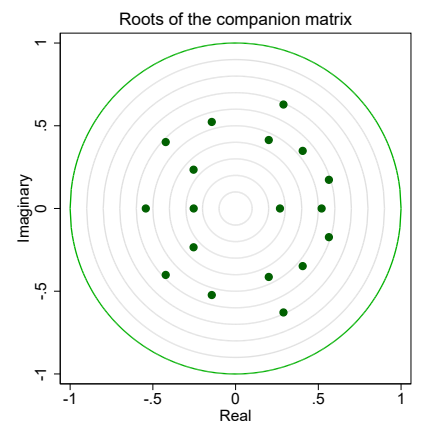

(c) After crisis (2008m12 - 2015m10)

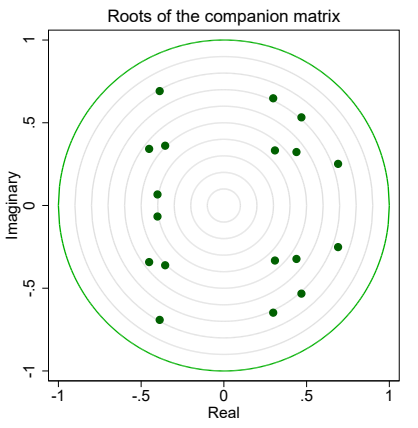

As pointed out by Luetkepohl (2011), if the modulus of each eigenvalue of the matrix A is strictly less than one, then the estimated VAR is stable. In our case, we can infer from Figure 10 that the eigenvalues are inside the unit circle, indicating that the system is stable. In other words, all variables in the system are jointly stationary, and our model is "non-explosive". 